\title{
A Review of the Hydraulic Transient and Dynamic Behavior of Hydropower Plants with Sloping Ceiling Tailrace Tunnels
}

\author{
Wencheng Guo \\ School of Hydropower and Information Engineering, Huazhong University of Science and Technology, \\ Wuhan 430074, China; wencheng@hust.edu.cn; Tel.: +86-15926202836
}

Received: 9 July 2019; Accepted: 9 August 2019; Published: 21 August 2019

check for updates

\begin{abstract}
The sloping ceiling tailrace tunnel is a novel tailrace tunnel system for hydropower plants. The design, operation, and maintenance of hydropower plants with sloping ceiling tailrace tunnels are based on the calculation and analysis of hydraulic transients and dynamic behavior. Research achievements have provided guidance and a basis for the safe, stable, and efficient operation of hydropower plants with sloping ceiling tailrace tunnels. Based on research achievements, sloping ceiling tailrace tunnels have been applied to more and more hydropower plants. This review paper gives a systematic literature investigation on the hydraulic transient and dynamic behaviors of hydropower plants with sloping ceiling tailrace tunnels. First, the appearance and development of sloping ceiling tailrace tunnels are stated. Key issues in the hydraulic transient and dynamic behaviors of hydropower plants with sloping ceiling tailrace tunnels are illuminated. Then, research achievements on six issues (i.e., the working principles of sloping ceiling tailrace tunnels, the shape design of sloping ceiling tailrace tunnels, the free surface pressurized flow characteristics in sloping ceiling tailrace tunnels, numerical simulations of transient processes for hydro-turbine governing systems with sloping ceiling tailrace tunnels, the stability of hydro-turbine governing systems with sloping ceiling tailrace tunnels, and the transient process control of hydro-turbine governing systems with sloping ceiling tailrace tunnels) are elaborated. Finally, future research trends are presented. In future research, fluid-solid coupling of the tunnel wall and free surface pressurized flow in sloping ceiling tailrace tunnels is worth studying. For hydropower plants with sloping ceiling tailrace tunnels, a combined operating scheme with thermal power and wind power should be explored.
\end{abstract}

Keywords: hydropower plant; sloping ceiling tailrace tunnel; hydro-turbine governing system; hydraulic transient; dynamic behavior

\section{Introduction}

With the profound development of hydroelectric energy, more and more large-scale hydropower plants are being built on the upper and middle reaches of rivers [1,2]. Those rivers usually are located in alpine and gorge regions [3]. The powerhouse of hydropower plants is arranged underground, and the length of the pipeline system is about $1000 \mathrm{~m}$ [4]. According to the requirements for calculations of regulation guarantees for hydropower plants, the surge tank always needs to be set $[5,6]$. If the hydropower plant has a great flow discharge and a small working head, the section area of the surge tank is extremely large to guarantee the stability of surge wave oscillation [7,8]. Generally, the underground powerhouse, main-transformed cavern, and surge tank are arranged in a region with a length less than $150 \mathrm{~m}$. Then the scale of the underground cavern group is huge. There is enormous difficulty in the excavation, support, and surrounding rock stability of the huge underground cavern group. The layout of the surge tank also faces significant challenges. If there is a novel tailrace tunnel system that can replace the downstream surge tank, the above obstacles can be overcome. 
In order to overcome the above obstacles, tailwater open channels [9] have been studied by many researchers. In some conditions, the tailwater open channel has an obvious technical advantage in replacing the downstream surge tank. Specifically, the variation range of tailwater levels is small, and the flood period is short. Under the above conditions, the height of the tailrace tunnel is small, and the flow inertia time constant can be decreased obviously [10]. Then, the dynamic behavior of hydropower plants is excellent [11]. However, the major defect of a hydropower plant with a tailwater open channel is that the power generation must be stopped during the flood period [12]. Thus, the economic advantages of tailwater open channels are bad.

Compared to downstream surge tanks, pressurized tailrace tunnels, and tailwater open channels, sloping ceiling tailrace tunnels (SCTTs) are a kind of novel tailrace tunnel system that can replace the downstream surge tank [13].

The layout of a hydropower plant with an SCTT is shown in Figure 1. SCTTs were first proposed by Soviet Union engineers and were adopted in the Heping hydropower plant in Vietnam [13]. Then, SCTTs were introduced in China and successfully applied in several large-scale hydropower plants, such as the Pengshui hydropower plant, the Three Gorges underground hydropower plant, the Gongguoqiao hydropower plant, and the Xiangjiaba hydropower plant in China. The application of an SCTT overcomes the obstacles of the layout of downstream surge tanks and the excavation of underground cavern groups. The novel tailrace tunnel system has obvious economic and technical advantages. Unfortunately, Reference [13] is only an application case of an SCTT in a specific hydropower plant. The working principles and shape design theory were not studied in Reference [13].

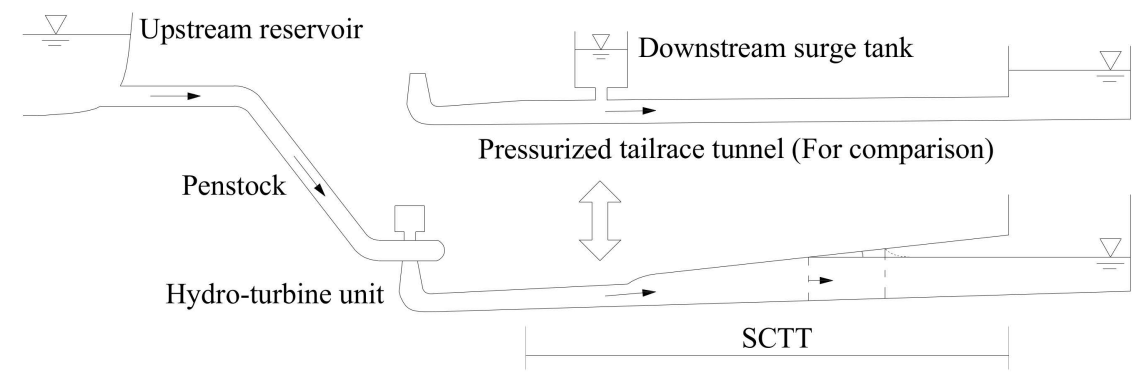

Figure 1. Layout of a hydropower plant with a sloping ceiling tailrace tunnel (SCTT).

Hydraulic transient and dynamic behaviors are the key aspects for guaranteeing the safe, stable, and efficient operation of hydropower plants [14,15]. For a hydropower plant with an SCTT, the design, operation, and maintenance are all based on the results of the calculation and analysis of hydraulic transient and dynamic behaviors [16,17]. The layout and flow pattern of SCTTs are obviously different from those of pressurized tailrace tunnels. The tailrace tunnel system is a significant component of hydropower plants and has an important and primary effect on the hydraulic transient and dynamic behaviors of the whole hydropower plant. As a result, the hydraulic transient and dynamic behaviors of a hydropower plant with an SCTT are significantly different from those of a hydropower plant with a pressurized tailrace tunnel. Thus, the theories and technologies for the design, operation, and maintenance of hydropower plants with pressurized tailrace tunnels cannot be applied to a hydropower plant with an SCTT directly.

Moreover, as a novel tailrace tunnel system, there has been little related research where an SCTT appears. The traditional and classical literature of hydraulic transient and dynamic behaviors of hydropower plants has mainly focused on hydropower plants with pressurized tailrace tunnels. The representative literature has stated as follows: In Reference [14], the modeling and dynamic behaviors of hydropower plants were systematically introduced. However, the tailrace tunnel system of the considered hydropower plant was a pressurized tailrace tunnel. In Reference [15], the transient process and control for a hydropower station with a super long headrace tunnel were reviewed. The emphasis of Reference [15] was a pressurized headrace tunnel and a surge tank. In Reference [16], the basic theory and computing methods for hydraulic transients of hydropower plants were introduced. 
Unfortunately, SCTTs were still not considered and studied. The lack of theories and technologies for design, operation, and maintenance directly restricts the popularization and application of SCTTs. The hydraulic transient and dynamic behavior of hydropower plants with SCTTs should be specialized.

After the appearance of SCTTs, wide attention was paid by researchers and engineers. Based on the theoretical system of transient processes and the particularity of SCTTs, the key issues in the hydraulic transient and dynamic behaviors of hydropower plants with SCTTs consist of the following six aspects:

Issue 1. Working principles of SCTTs;

Issue 2. Shape design of SCTTs;

Issue 3. Free surface pressurized flow (FSPF) characteristics of SCTTs;

Issue 4. Numerical simulations of transient processes for hydro-turbine governing systems (HTGSes) in SCTTs;

Issue 5. Stability of HTGSes with SCTTs;

Issue 6. Transient process control of HTGSes with SCTTs.

Issues 1, 2, and 3 focus on the SCTT itself, including problems on basic principles, shape, and flow. Issues 4, 5, and 6 focus on HTGSes with SCTTs, including numerical simulations, stability, and the control of transient processes. In terms of the above six issues, a lot of research achievements have been obtained. The research achievements provide a basis and guidance for the design, operation, and maintenance of hydropower plants with SCTTs. Based on the obtained research achievements, SCTTs have been applied in more and more hydropower plants.

This paper aims to systematically summarize the existing research achievements on the hydraulic transient and dynamic behavior of hydropower plants with SCTTs, which can help the readers understand the research progress on that topic clearly. Then, future research trends are pointed out to promote the development of the theories and technologies on hydraulic transient and dynamic behaviors.

In terms of Issue 1, it is discussed in References [18-23]. References [18-23] reveal the working principle of SCTTs by using theoretical analysis, model tests, and numerical simulations. The application scope of SCTTs is pointed out. Those research achievements are systematic and deep.

Regarding Issues 2 and 3, they are discussed in References [18,24-32]. Shape design is the core work in the design of SCTTs. FSPF characteristics in SCTTs are the source of the nonlinearity and complexity that affect the hydraulic transient and dynamic behaviors of hydropower plants with SCTTs. References [18,24-32] proposed shape design methods and procedures for SCTTs, which can be applied in actual engineering conveniently. The FSPF characteristics in SCTTs have been revealed by different simulation models and methods.

In terms of Issue 4, it is discussed in References [24,33-38]. The numerical simulation of transient processes is the basis for describing the dynamic processes and characteristics of HTGSes with SCTTs. Several numerical simulation methods were proposed in References [24,33-38]. Numerical simulation methods can realize the calculation of transient processes for HTGSes with SCTTs. Different numerical simulation methods have different advantages and disadvantages.

Regarding Issue 5, it is discussed in References [39-44]. The stability of an HTGS directly relates to the stable operation of a hydropower plant. In References [39-44], mathematical modeling, stability analysis methods, and stability performance regarding the stability of HTGSes with SCTTs were studied. Those research achievements are also systematic.

In terms of Issue 6, it is discussed in References [45-52]. The control of transient processes relates to the regulation quality of hydropower plants with SCTTs. In References [45-52], the regulation quality of HTGSes with SCTTs was studied, and several control strategies were proposed. By using the proposed control strategies, the dynamic performance of an HTGS with an SCTT can be improved.

This review paper gives a systematic literature investigation about the hydraulic transient and dynamic behavior of hydropower plants with SCTTs. The literature includes References [18-52]. 
The research in the literature reviewed in this paper has universality. The work is based on general models and methods. A case study was applied for verification. Thus, the conclusions are general and valid for all hydropower plants with SCTTs. In Section 2, the working principle of SCTTs is explained based on References [18-23]. In Section 3, the shape design of SCTTs is discussed, and the design methods are presented based on References [18,24-27]. The FSPF characteristics in SCTTs are described and different simulation methods are presented based on References [28-32]. In Section 4, the numerical simulation of a transient process for HTGSes with SCTTs is described based on References [24,33-38]. In Section 5, the stability of HTGSes with SCTTs is discussed based on References [39-44]. In Section 6, the transient process control of HTGSes with SCTTs is explained based on References [45-52]. In Section 7, the conclusions are given, and future research trends are presented.

\section{Working Principle of SCTTs}

The working principle of an SCTT is the basis for the popularization and application of SCTTs in hydropower plants. The economic and technical advantages of SCTTs come from their unique working principles. Many research works have been carried out to reveal the working principle of SCTTs.

In this review paper, the considered process is the transient process of hydropower plants with SCTTs. A hydropower plant with an SCTT is composed of a pipeline system and a hydro-turbine unit. During the transient process, the pipeline system and hydro-turbine unit enter an unsteady state. For the pipeline system under a transient process, the modeling is based on the pressurized and open-channel unsteady flow theory. The basic equations of the pipeline system usually contain a dynamic equation and a continuity equation of unsteady flow. For the hydro-turbine unit in the transient process, the modeling is based on the real-time power output and regulation theory. The basic equations of a hydro-turbine unit usually contain the characteristic equations of hydro-turbines, power output equations of generators, and regulation equations of governors. In some particular cases, the modeling of hydropower plants may be simplified based on the research purpose and need. For the transient process of hydropower plants with SCTTs considered in this paper, the main sources of disturbance are external disturbances, including load disturbances and frequency disturbances. The uncertainty mainly contains the uncertainty of working head and load demand. The model reality mismatch is a kind of objective existence, because the modeling is always based on several assumptions. For the obtained mathematical model, comparisons and verifications with model experiment results or field measurement results can check the difference and precision of the model. Based on the model experiment results or field measurement results, the obtained mathematical model can be improved and confirmed (whether the accuracy requirements are met).

In Reference [18], Yang et al. explained the working principles of SCTTs systematically. A feature of an SCTT is that the tailwater level is linked up to the arbitrary section of the tunnel roof. Then, the whole tailrace tunnel is divided into two parts, i.e., a pressurized flow section and a free surface flow section. When the tailwater level is low, the inundated depth of the hydro-turbine is small. However, the free surface flow section is long, and the pressurized flow section is short. During the transient process, the negative water hammer pressure is small. As a result, the minimum pressure at the section of the inlet of the draft tube does not exceed the code requirement. With the rise of the tailwater level, the length of the free surface flow section becomes shorter, and the length of the pressurized flow section becomes longer. The negative water hammer pressure becomes greater until the whole SCTT is the pressurized flow section. During the rise process of the tailwater level, the inundated depth of the hydro-turbine becomes greater gradually, and the average flow velocity in the pressurized flow section becomes smaller gradually. The positive and negative effects cancel each other out. The hydropower plant can operate under safe conditions. Thus, the working principle of an SCTT is that the SCTT plays the role of a downstream surge tank by using the change in tailwater level.

The application scope of SCTTs mainly depends on the length of the tailrace tunnel and the variation in amplitude of the tailwater level. If the variation in amplitude of the tailwater level is great, it is favorable to adopt an SCTT. An SCTT can eliminate the problem of minimal pressure at 
the section of the inlet of the draft tube. The other advantage is that an SCTT has no restriction in the tailwater level.

The hydraulic characteristics of the unsteady flow in SCTTs were studied by using the model test in Reference [19]. Specifically, the hydraulic model test was based on a real hydropower plant. The hydraulic characteristics of the unsteady flow in an SCTT, including the pressure fluctuation process at the inlet of the draft tube and the water level fluctuation process at the free surface flow section, were measured, and the results are shown in Figure 2. The model test results indicated that the head loss in the outlet of the SCTT was small under the operating conditions of a low tailwater level. Under the operating conditions of a high tailwater level, the amplitude of negative pressure at the roof of the SCTT was still small. The controlling parameters of the transient process could meet the code requirements. Moreover, the SCTT could adapt to the change in the tailwater level.

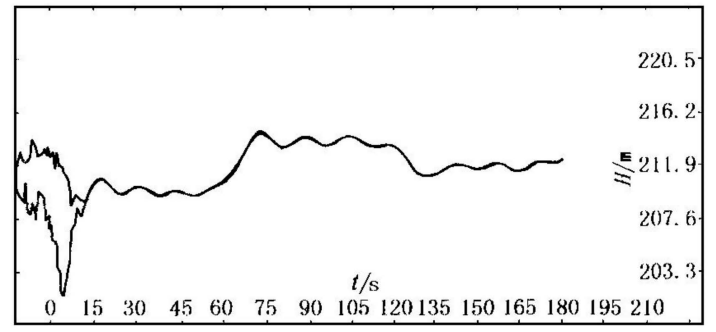

(a)

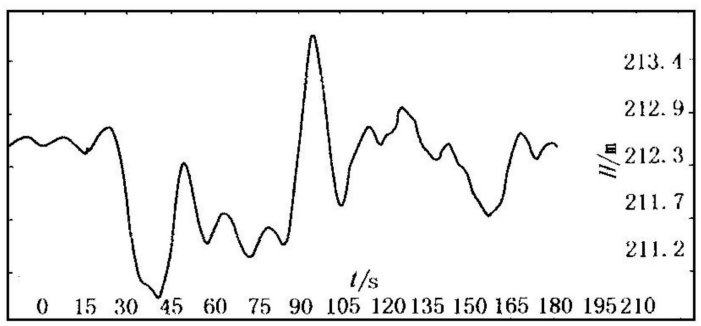

(b)

Figure 2. Experimental results for the hydraulic characteristics of unsteady flow in an SCTT. (a) Pressure fluctuation process at the inlet of the draft tube. (b) Water level fluctuation process in the free surface flow section [19].

By using the model test and numerical simulation, Lai et al. [20] studies the working principle of an SCTT. Three typical operating conditions, i.e., a large fluctuation transient process, a small fluctuation transient process, and a hydraulic disturbance transient process, were analyzed.

(1) Large fluctuation transient process: The hydraulic characteristics of the unsteady flow in an SCTT mainly depend on the tailwater level. When the tailwater level is low, the unsteady flow in an SCTT is actually the free surface unsteady flow. When the tailwater level is higher than the outlet roof of the SCTT, the unsteady flow in the SCTT is actually the pressurized unsteady flow. When the tailwater level is around the middle of the section, there exists FSPF in the SCTT. The SCTT can replace the downstream surge tank.

(2) Small fluctuation transient process: During the small fluctuation transient process, the dynamic quality mainly depends on the governor parameters. The dynamic response of the hydro-turbine unit frequency is a periodic fluctuation. The period of the frequency fluctuation is the same as that of the FSPF in an SCTT. The results indicated that the effect of an SCTT is similar to that of a downstream surge tank.

(3) Hydraulic disturbance transient process: During the small fluctuation transient process, the setting of the governor parameters is the key aspect for the stable operation of the hydro-turbine unit. On the one hand, an SCTT can reduce the unfavorable effect of flow inertia of the pressurized flow section in an SCTT. On the other hand, the water level fluctuation in an SCTT makes the settling time become longer.

In Reference [21], Xue et al. studied a model test of the hydraulic transient process in the Three Gorges underground hydropower plant in an SCTT. The model contained a model pipeline system and a model hydro-turbine unit. The closing law of guide vanes was applied, and the two-stage rule and the optimal inflexion point were determined (Figure 3). The test results proved that the two-stage closing law of guide vanes had an obviously favorable effect on reducing the pressure at the section of the inlet of the draft tube and the hydro-turbine unit frequency (Figure 4). SCTTs are a novel design 
scheme for tailrace tunnels. The application of SCTTs can reduce the excavation of mountain and investment outlays.

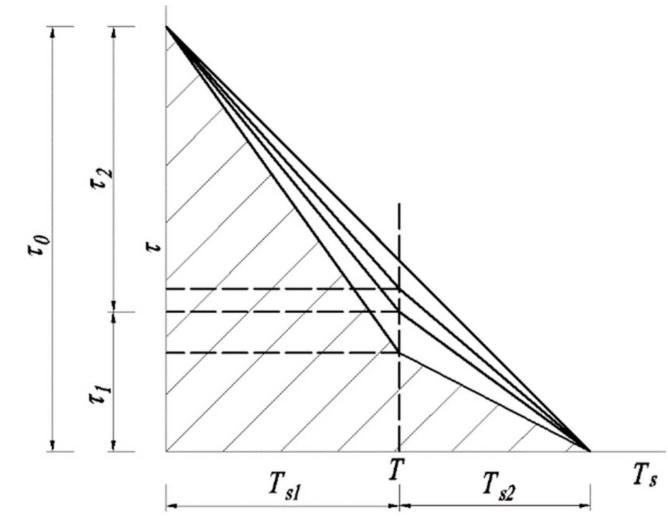

Figure 3. One-stage and two-stage closing laws of guide vanes [21].

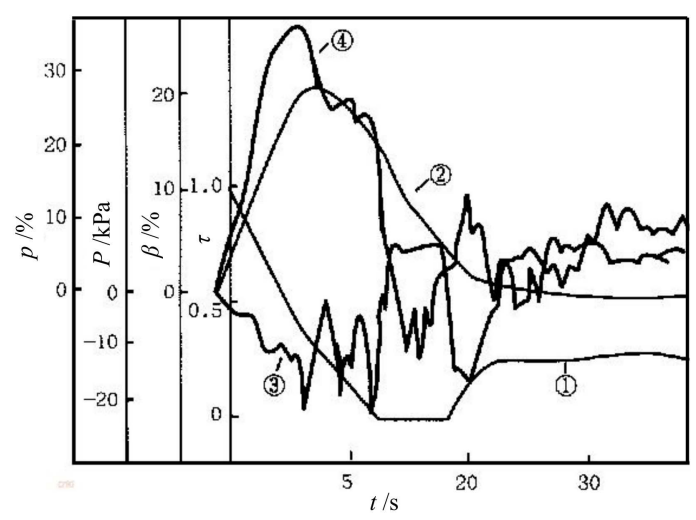

Figure 4. Transient process of a hydropower plant with an SCTT under the two-stage closing law of guide vanes [21].

During the design process of the Three Gorges underground hydropower plant, three schemes for the tailrace tunnel system, i.e., a pressurized tailrace tunnel without a downstream surge tank, a pressurized tailrace tunnel with a downstream surge tank, and an SCTT, were compared comprehensively [22]. By using the model test and computational analysis, the scheme for the tailrace tunnel system was optimized. The final selected scheme was an SCTT, and that scheme was put into practice. The SCTT scheme of the Three Gorges underground hydropower plant provides a reference that is significant for other hydropower plants.

In Reference [23], Miao et al. investigated the approximate calculation formula for a vacuum at the section of the inlet of the draft tube in a hydropower plant with an SCTT under load rejection operating conditions (Figure 5). The elasticity of the water and tunnel wall was neglected. The derivation was based on a Bernoulli equation of the unsteady gradually varied flow. The static vacuum term, dynamic vacuum term, and inertial vacuum term were discussed. Then, the approximate calculation formula for the vacuum at the section of the inlet of the draft tube for the hydropower plant with an SCTT under load rejection operating conditions was derived and is shown in Equation (1). The calculation result of that formula was close to the model test result. If the closing rate of guide vanes is slow and the tailrace tunnel is short, that approximate calculation formula can be applied in the preliminary design of a hydropower plant with an SCTT. 


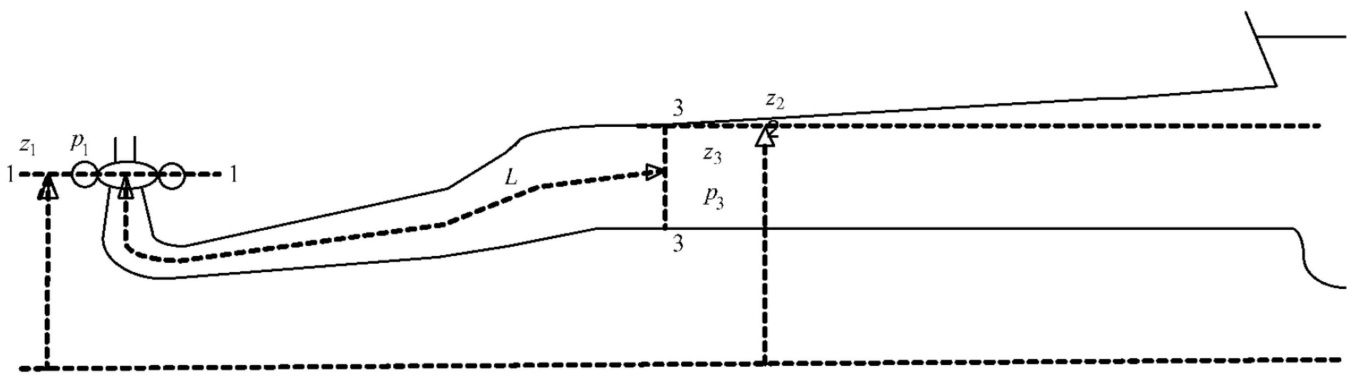

Figure 5. Schematic diagram for the profile of an SCTT [23].

Equation (1) is

$$
\frac{P_{v}}{\gamma_{\max }}=\max \left\{\begin{array}{l}
z_{1}-z_{20}+\eta_{\omega} \frac{V_{10}^{2}}{2 g}+\frac{\beta}{g} \frac{Q_{0}}{T_{s}} \int \begin{array}{l}
L_{P 0} \\
0
\end{array} \frac{1}{f_{t}} \mathrm{~d} s \\
z_{1}-z_{20}+i_{a} \omega T_{s}+\frac{\beta}{g} \frac{Q_{0}}{T_{s}} \int \begin{array}{l}
L_{P 0}-\omega T_{s} \\
0
\end{array} \frac{1}{f_{t}} \mathrm{~d} s
\end{array}\right.
$$

In order to verify the research results, measurements in a laboratory were adopted in References [19-23]. Specifically, in Reference [19], the hydraulic characteristics of the unsteady flow in an SCTT were studied by using a model experiment. In References [19-23], the numerical simulation results and theoretical analysis results were compared to and verified with the test data of model experiments.

The effect of the change in water potential on the level of electricity production of a hydropower plant with an SCTT is also an important subject. When the water potential decreases, the hydro-turbine net head becomes smaller. As a result, for the hydropower plant, the operating point on the characteristic curves of the hydro-turbine moves to a new location. Different operating points correspond to different hydro-turbine efficiencies. When the hydro-turbine net head decreases, the hydro-turbine efficiency may become smaller or greater. The changes in the hydro-turbine net head and efficiency change the level of electricity production of the hydropower plant together. Therefore, the change in water potential has a complicated effect on the level of electricity production of a hydropower plant with an SCTT. That research subject needs to be studied to reveal the effect mechanism of the change in water potential and the change law of the level of electricity production. By improving the model of this paper, it is possible to take the effect of the change in water potential into account. The operating point and hydro-turbine efficiency are determined by the transfer coefficients of the hydro-turbine. By considering the actual changes in the net head and transfer coefficients, the effect of the change in water potential on the level of electricity production can be studied.

\section{Shape Design of SCTTs and FSPF Characteristics of SCTTs}

\subsection{Shape Design of SCTTS}

The shape design is the core work of the design of SCTTs. Yang et al. [18] proposed detailed procedures for the shape design of SCTTs, as follows:

Step 1. When the tailwater level is the lowest, the free surface flow section should be extended to the location before the outlet section of the draft tube. Then the length of the pressurized flow section can be as short as possible;

Step 2. According to the allowable maximum flow velocity at the outlet section of the tailrace tunnel and the distance to the other tailrace tunnel, the elevation and width of an SCTT can be determined;

Step 3. For the tailrace tunnel, select the top elevation of the outlet section and the slopes of the roof and floor to meet the transient process requirements when the whole tailrace tunnel is pressurized flow;

Step 4. The value of the roof slope of the tailrace tunnel is favorable for dealing with the problem of the FSPF; 
Step 5. The difference in the elevation and width between the SCTT and the draft tube is connected to a transition section. The buttock line of the roof of the transition section is a parabola.

For a hydropower plant with an SCTT, draft tube gates are still needed. Because there is no tailrace surge tank, the draft tube gates of hydropower planta with SCTTs are usually placed at the joint of the draft tube and the SCTT. Specifically, at the joint of the draft tube and the SCTT, a gate chamber is built to place the draft tube gates.

In Reference [24], Deng et al. studies the shape design of SCTTs and explained the operating features of SCTTs. A hydropower plant with two units and an SCTT was selected as the object for the analysis (Figure 6), and several achievements were obtained. The roof slope has a significant effect on the whole tailwater system. A small change in the roof slope of an SCTT can cause a significant change in the pressure and discharge. The general trend is that the amplitude of pressure oscillation and the vacuum at the section of the inlet of the draft tube become smaller when the roof slope of an SCTT increases. However, when the roof slope of an SCTT exceeds a certain value, that effect becomes inconspicuous. The floor slope of an SCTT almost has no influence on the transient process of a whole tailwater system. When the floor slope of an SCTT decreases, the amplitude of pressure oscillation becomes smaller, and the vacuum at the section of the inlet of the draft tube can meet the design requirement easily. The width of an SCTT only has a slight effect on the amplitude of pressure oscillation, while it has a significant effect on the vacuum at the section of the inlet of the draft tube.

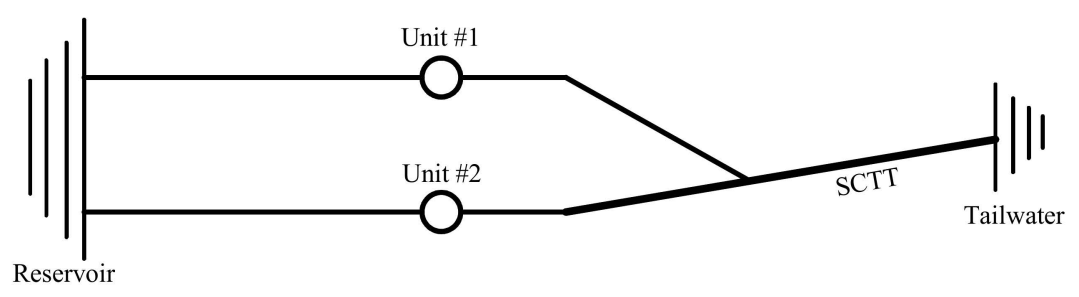

Figure 6. Schematic diagram for the hydropower plant with two units and an SCTT [24].

The design method for roof slope and the shape of an SCTT was also studied by Zhang et al. [25]. Based on the approximate calculation formula for the vacuum at the section of the inlet of the draft tube for a hydropower plant with an SCTT under load rejection operating conditions, the calculation formula for the roof slope was derived. Then the procedural and quantitative shape design method of an SCTT was proposed. The proposed design method was verified by comparing it to the model test results. Detailed procedures for the procedural and quantitative shape design method of an SCTT are presented as follows:

Step 1. Determine the flow velocity in the draft tube and the section shape of the tailrace tunnel approximately;

Step 2. Let the maximal vacuum at the section of the inlet of the draft tube be less than $5 \mathrm{~m}$ under the lowest tailwater level. Then determine the maximal length of the pressurized flow section;

Step 3. Determine the highest elevation of the roof for the outlet section of the draft tube;

Step 4. Determine the roof slope of the SCTT;

Step 5. Determine the floor elevation of the SCTT based on the allowable maximal flow velocity at the outlet section of the SCTT under the lowest tailwater level.

In References [26,27], two actual projects, i.e., the Pengshui hydropower plant and Xiangjiaba hydropower plant, were introduced to explain the application of SCTTs.

The Pengshui hydropower plant [26] was the first hydropower plant with an SCTT in China. During the construction of the Pengshui hydropower plant, there were few references. Through a lot of research, several key technical problems were overcome. SCTTs are effective and feasible tailrace tunnels for hydropower plants with large amplitude variations in the tailwater level, great flow, and a small head. SCTTs are an alternative solution to downstream surge tanks. 
The Xiangjiaba hydropower plant [27] was also a successful attempt at an SCTT. For the Xiangjiaba hydropower plant (with an SCTT), a large fluctuation transient process, small fluctuation transient process, and hydraulic disturbance transient process could meet the requirements of design specifications. The SCTT replaced the downstream surge tank. Then the excavation of underground cavities could be decreased significantly. Compared to the scheme of the downstream surge tank, the head loss under the scheme of the SCTT was also reduced. Thus, the scheme of the SCTT had an obvious economic advantage.

Model experiments were used to verify the research results in References $[25,27]$. Specifically, in Reference [25], the proposed theoretical design method was verified by comparing it to the model experiment results. In Reference [27], the numerical simulation results of the transient process were compared to the test data of the model experiment.

It should be noted that during the transient process, the pressure caused by the mixed pressurized and free surface flow in the SCTT was not very great. For the general structural design of a tailrace tunnel, that pressure is safe and cannot lead to the destruction and collapse of the tunnel.

\subsection{FSPF Characteristics in SCTTs}

Compared to a pressurized tailrace tunnel, the particularity of an SCTT is caused by the FSPF characteristics in the tunnel. The FSPF characteristics introduce nonlinearity into the dynamic system. Nonlinear and complicated FSPF in SCTTs is the main factor that affects the hydraulic transient and dynamic behaviors of hydropower plants with SCTTs.

For an SCTT under steady flow conditions, the interface between free surface flow and pressurized flow moves back and forth in a small range. Aiming at that phenomenon, Li et al. [28] studied flow characteristics in SCTTs by using the water filling ratio theory of free flow tunnels and the interface stability theory of gas-liquid two-phase flow. The relationship between the flow in SCTTs and the water filling ratio was obtained and is shown in Figure 7. The results indicated that the unstable flow section could not cause the FSPF and gas detention phenomenon. The length and fluctuation range of the unstable flow section at the interface between free surface flow and pressurized flow were affected by the roof slope and flow velocity in the tailrace tunnel directly.

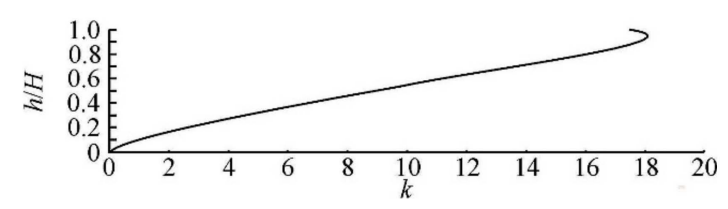

Figure 7. Relationship between the flow in an SCTT and the water filling ratio [28].

During transient processes, the unsteady flow in an SCTT is always FSPF. That complicated flow has obvious three-dimensional (3D) flow characteristics. The accurate simulation of FSPF is directly related to the transient process parameters of hydropower plants. In Reference [29], An et al. carried out a numerical simulation of FSPF in an SCTT by using the 1D-3D coupled method (Figure 8) and then compared the obtained results to those obtained from the virtual slit method (Figure 9). In Figure 8, the 1D numerical simulation method was conducted by using the software Topsys, and the 3D numerical simulation method was conducted by using the software Fluent. The 1D-3D coupled simulation was realized by combining Topsys and Fluent. Based on the above analysis, the differences between and applicability of those two methods were explained and revealed. The results indicated the following:

(1) The calculation results of the 1D-3D coupled method had good agreement with the test data based on field measurements. The three stages of the FSPF in an SCTT, i.e., the water recession process, volume increase process, and backwater process, could be accurately simulated. The fluctuation processes of the interface and water surface profiles of the FSPF in an SCTT could be accurately caught (Figure 10); 
(2) The distortion of the numerical simulation of the FSPF in an SCTT through the use of the virtual slit method came from the water recession process. An improvement in the virtual slit method is necessary. It is suggested that the effect of wall adhesion and surface tension should be considered.

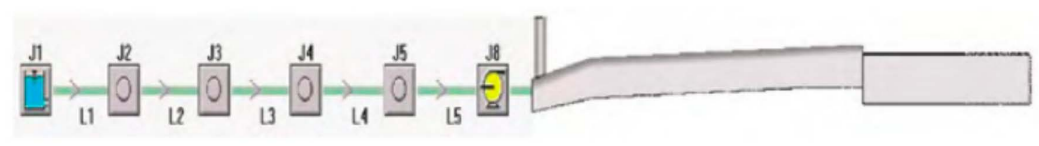

Figure 8. Schematic diagram for the 1D-3D coupled simulation model [29].

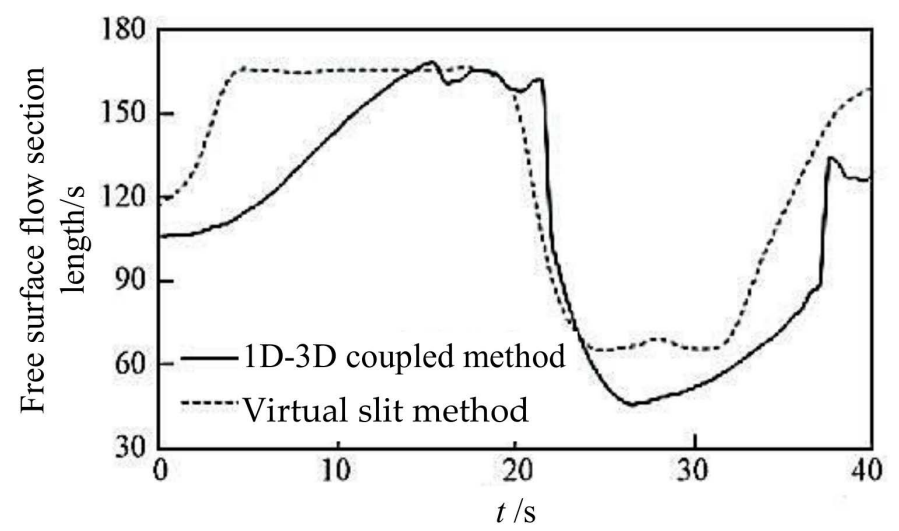

Figure 9. Comparison between the fluctuation processes of the free surface flow section length of the 1D-3D coupled method and the virtual slit method [29].

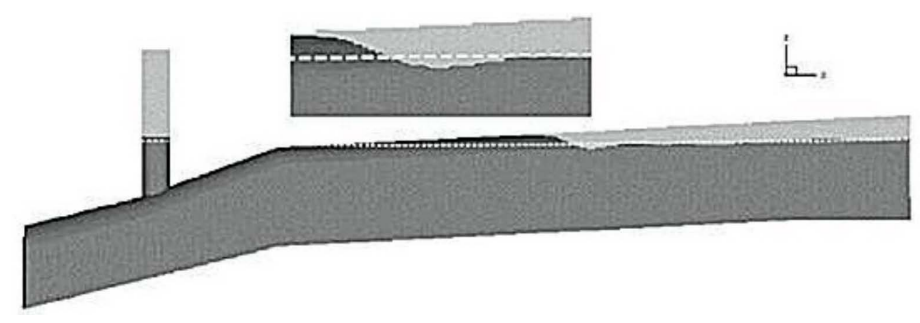

Figure 10. Comparison between the interface and water surface profiles of the 1D-3D coupled method and the virtual slit method [29].

In Reference [30], Cheng et al. studies the simulation of FSPF in an SCTT by using a 3D computational fluid dynamics (CFD) method with a volume of fluid (VOF) model. The simulation was carried out by using the software Fluent, and a schematic diagram of the domain and boundary conditions of the CFD-VOF simulation in Fluent is shown in Figure 11. Based on the CFD-VOF simulation method, the transient process of the flow in an SCTT under load rejection operating conditions was simulated. The results were compared to the model test results (Figure 12). The generation of large air bubbles was also analyzed. The results indicated that the CFD-VOF simulation method could accurately simulate the FSPF processes and characteristics in an SCTT. The flow in an SCTT under transient processes is special. There is an interface in the FSPF in an SCTT. That interface moves back and forth. The generation of large air bubbles is an inevitable phenomenon for FSPF in an SCTT. 


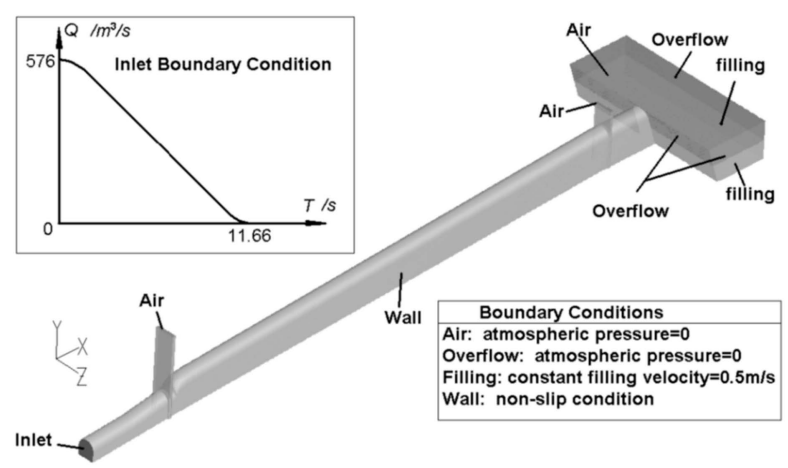

Figure 11. Schematic diagram of the domain and boundary conditions of the computational fluid dynamics (CFD)-volume of fluid (VOF) simulation [30].

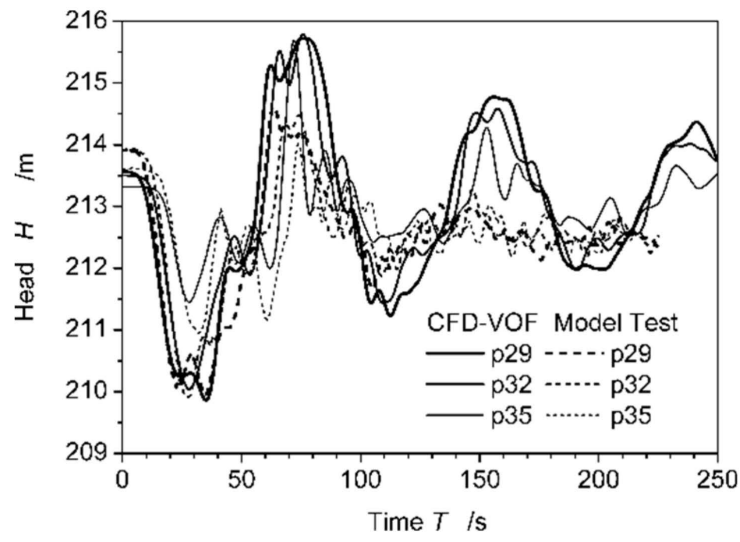

Figure 12. Comparison between the heads in different positions of the CFD-VOF results and the model test results [30].

To overcome the dense space problem of underground caverns in large-scale hydropower plants, a tailrace tunnel and diversion tunnel can be combined to form a new type of tailrace system, i.e., a tailrace and diversion combined tunnel. A tailrace and diversion combined tunnel is a generalization of an SCTT and has been applied in several large-scale hydropower plants in China, such as the Wudongde hydropower plant and the Baihetan hydropower plant. For the tailrace and diversion combined tunnel, air-water interaction and flow break are two key issues that were studied in References [31] and [32], respectively.

In Reference [31], Zhang et al. studied the issue of air-water interaction in the tailrace and diversion combined tunnel by using the experimental method. The experimental model is based on a real hydropower plant with a tailrace and diversion combined tunnel. The observation of air-water interaction in the tunnel was carried out, and the change processes of pressure oscillation at different monitoring points in the tailrace tunnel were obtained (Figure 13). According to the experimental results, the air-water interaction in the tunnel had a significant effect on the water flow characteristics and could be divided into four types based on the initial tailwater level. The four types are called single air pocket motion, multiple air pocket motion, interfacial instability, and negligible interaction. It was confirmed that the initial relative tail water was the controlling variable in determining the type of interaction. The multiple air pocket motion condition and the interfacial instability condition had a critical effect on the maximum pressure during the transition. As the interactions between the air and water phases played an important role in the conditions of the multiple air pocket motion and the interfacial instability, a two-phase model may reproduce and predict the flow better. Within a certain range of the initial tailwater level, the air-water interaction effect in a tunnel cannot be ignored. The air-water interaction effect in a tunnel is unfavorable for a hydropower plant and should be seriously controlled. 


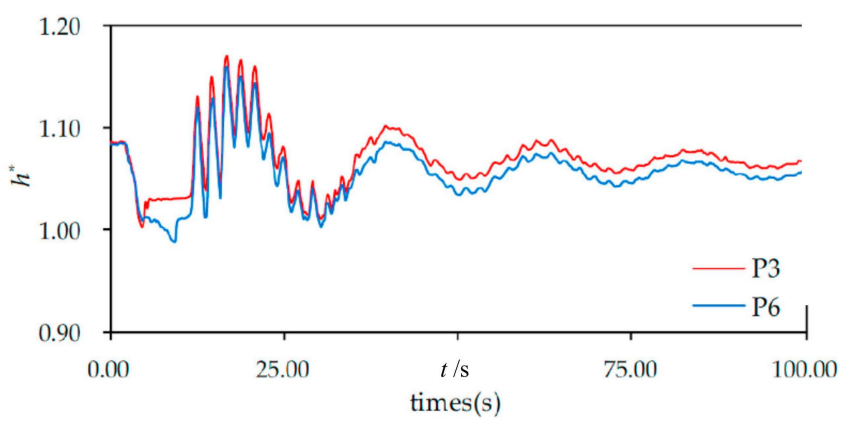

Figure 13. Change processes of pressure oscillation at different monitoring points in a tailrace tunnel [31].

For the tailrace and diversion combined tunnel, the flow at the combination point is special and is complicated under operating conditions with a low tailwater level. Specifically, the water depth is small, and the flow velocity is great. During the load rejection process, a special and dangerous hydraulic phenomenon, i.e., flow break, may happen at the combination point of the tailrace tunnel and the diversion tunnel. In Reference [32], Yang et al. studies the mechanism of the flow break in a tailrace and diversion combined tunnel by using a 1D numerical simulation method and a 3D numerical simulation method, respectively. The results indicated the following:

(1) When the tailwater level was low, the Froude number $\mathrm{Fr}$ at the combination point of the tailrace tunnel and diversion tunnel gradually approached 1 and then exceeded 1 after the load rejection (Figure 14). As a result, a wave break happened, and the supplement of reverse discharge was blocked (Figure 15). Therefore, $F r>1$ was the internal cause of flow break;

(2) After the load rejection, the water level in the downstream surge tank first decreased and then increased. During the stage of water level increase, it is necessary to supply enough water to the tunnel because of the effect of flow inertia. If the water supplement is insufficient, the water depth at the combination point of the tailrace tunnel and diversion tunnel further decreases. Hence, the flow break must have happened during the stage of water level increase;

(3) For the position and time of the occurrence of flow break, the results of the 1D numerical simulation method and the 3D numerical simulation method were consistent. Thus, the 1D numerical simulation method is feasible for the calculation of the transient process in a tailrace and diversion combined tunnel.

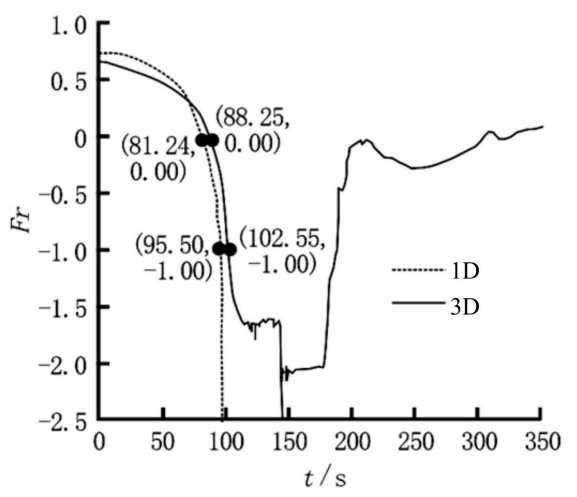

Figure 14. Change of the Froude number $F r$ at the combination point of the tailrace tunnel and diversion tunnel [32]. 

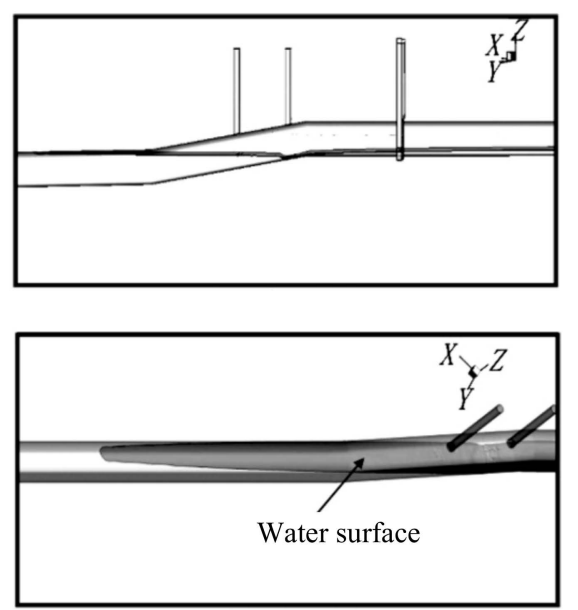

Figure 15. Water flow regime in the tailrace and diversion combined tunnel under flow break [32].

In References [30,32], the numerical simulation results of the transient process were compared to the test data of the model experiment. In Reference [29], the calculation results of the 1D-3D coupled method were verified by comparing them to the test data based on field measurements. In Reference [31], the air-water interaction in a hydropower station combining a diversion tunnel with a tailrace tunnel was studied by using a model experiment.

\section{Numerical Simulation of Transient Process for HTGSes with SCTTs}

A numerical simulation of the transient process is the basis for describing the dynamic processes and characteristics of HTGSes with SCTTs. Several numerical simulation methods have been proposed and applied to different kinds of hydropower plants with SCTTs [24,33-38].

In Reference [33], Cheng et al. studies the numerical simulation of a transient process for a hydropower plant with an SCTT. A joint simulation method that combined the FSPF in an SCTT and a conventional hydraulic transient process was proposed. That method was based on the tracking of the interface in the FSPF. For the pressurized flow section, the method of characteristics was applied. For the free surface flow section, the leapfrog explicit difference method was applied. The movement of the interface was calculated by combining the characteristic equations and boundary conditions of the pressurized flow section and free surface flow section. The time step and space step for the calculation of the pressurized flow section and free surface flow section were selected to be the same. By selecting an actual hydropower plant with an SCTT as an example, the transient process was simulated using the proposed method, and the regulation guarantee parameters were obtained (Figure 16). The results showed that the proposed method could accurately simulate the transient process for hydropower plants with SCTTs.

In Reference [24], an improved virtual slit method was applied by Deng et al. to simulate the transient process for HTGSes with SCTTs. For general unsteady flow in an open channel, the Preissman implicit scheme is unconditional convergence. However, for transient flow in an SCTT, the difference in the wave speeds between the free surface flow and pressurized flow is great. Then, the calculation results using the virtual slit method would not converge. The improved virtual slit method converts the basic equations of FSPF into standard hyperbolic equations. An upwind difference scheme is applied to solve dispersiveness. The improved virtual slit method has good convergence. During the calculation process, the movement of the interface of the FSPF is tracked in real time. Using the improved virtual slit method, a hydropower plant with an SCTT was selected as an example to simulate the transient process. The results for the change process of the head at a section in the SCTT are shown in Figure 17, indicating the effectiveness of the improved virtual slit method. 


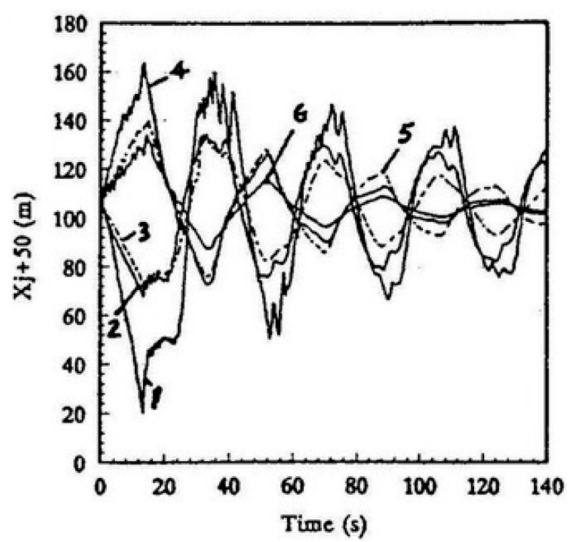

Figure 16. Fluctuation attenuation of the free surface pressurized flow (FSPF) in an SCTT under different operating conditions [33].

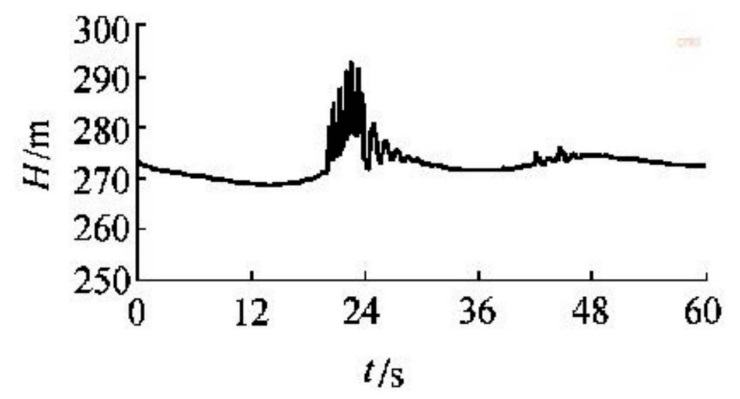

Figure 17. Change process of the head in a section of the SCTT [24].

Hydraulic disturbance is a typical transient process operating condition. In Reference [34], Zhou et al. studied the hydraulic disturbance transient process of a hydropower plant with an SCTT. The numerical simulation method in Reference [34] contains the method of characteristics for a pressurized pipeline, the improved virtual slit method for open channels, and a numerical simulation for state equations. The interface of the FSPF was tracked using the improved virtual slit method. The boundary conditions, including the upstream and downstream reservoirs, surge tank, branch pipe, hydro-turbine, governor, and generator, were also considered. Figure 18 shows the simulation results of the rotational speed and power output of a hydropower plant with an SCTT under hydraulic disturbance operating conditions. The simulation of the hydraulic disturbance transient process of a hydropower plant with an SCTT revealed the interactions between different hydro-turbine units.

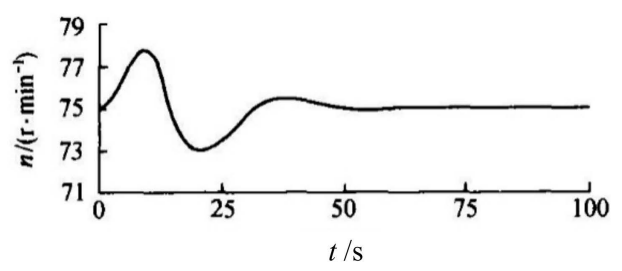

(a)

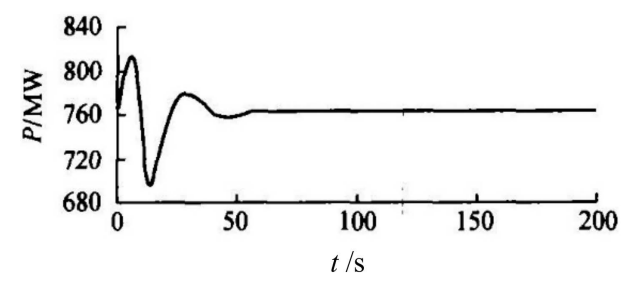

(b)

Figure 18. Simulation results of the rotational speed and power output of a hydropower plant with an SCTT [34]. (a) Rotational speed, (b) power output.

In Reference [35], Shu et al. proposed a Lax-Friedrichs slit method to simulate the transient process for HTGSes with SCTTs. First, the basic equations for free surface flow and pressurized flow could be transformed into one uniform form by using the slit model. Then, the difference equations could be obtained through discrete transformed equations using the Lax-Friedrichs scheme. Finally, by 
combining the difference equations, boundary conditions, and initial conditions, a numerical simulation of the transient process for HTGSes with SCTTs could be carried out. An actual hydropower plant with an SCTT was selected as an example to verify the method. The simulation results of the transient process were compared to the measured data. The comparison and analysis indicated that the error of the simulation results was small. The proposed Lax-Friedrichs slit method had good convergence.

For a hydropower plant with an SCTT, in some cases, the damping well is also set on the tailrace tunnel to improve safety and stability. Based on the mathematical model of transient flow and the Priessman assumption, the transient process for hydropower plants with SCTTs and damping wells was calculated (Figure 19) [36]. The simulation results were compared to the measured data. Based on the simulation results, the working characteristics of damping wells were analyzed. The results indicated the following:

(1) For a hydropower plant with an SCTT, the damping well can reflect the water hammer wave effectively. The effect of a damping well is similar to that of a surge tank. The surge wave oscillation in a damping well is mainly regulated by the governor. Hence, there is no critical stable sectional area issue;

(2) The scale of a damping well is smaller than that of a surge tank. Thus, the scheme of a damping well is more economical.

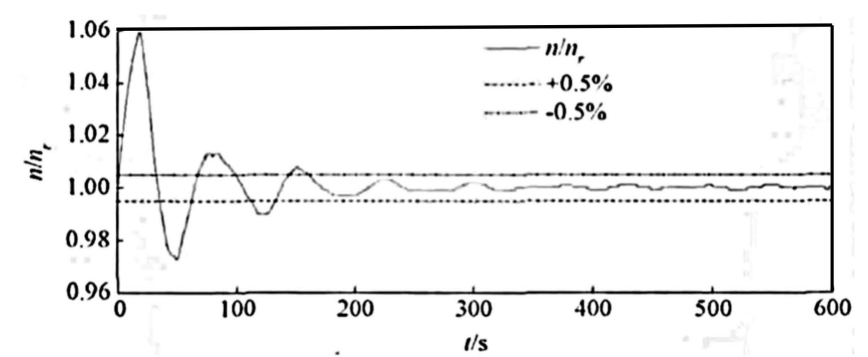

Figure 19. Fluctuation process of the rotational speed of a hydropower plant with an SCTT and a damping well under step load disturbance [36].

In References [37,38], two actual hydropower plants with SCTTs, i.e., the Three Gorges underground hydropower plant and the Xiangjiaba hydropower plant, were selected as examples to illuminate the characteristics and behaviors of the transient process.

For the Three Gorges underground hydropower plant (with an SCTT), the regulation guarantee parameters during the transient process were analyzed in Reference [37]. The maximum volume pressure almost had no relationship with the layout of the tailwater system and mainly depended on the flow inertia in the penstock and the closing law of the guide vane. The maximum rotational speed of the unit occurred during the closing process of the guide vane and mainly depended on the closing time of the guide vane and the discharge of the unit. The minimum pressure at the section of the inlet of the draft tube was affected by the flow inertia in the SCTT, the operating characteristics of the hydro-turbine, the closing law of the guide vane, and the tailwater level.

For the Xiangjiaba hydropower plant (with an SCTT), the transient process was analyzed in Reference [38]. The change process at the interface in the FSPF in the SCTT is shown in Figure 20. Under the effects of FSPF, the variation amplitude of pressure in the SCTT was small, and there was no air sac. The SCTT had no unfavorable effect on the safe and stable operation of the Xiangjiaba hydropower plant. 


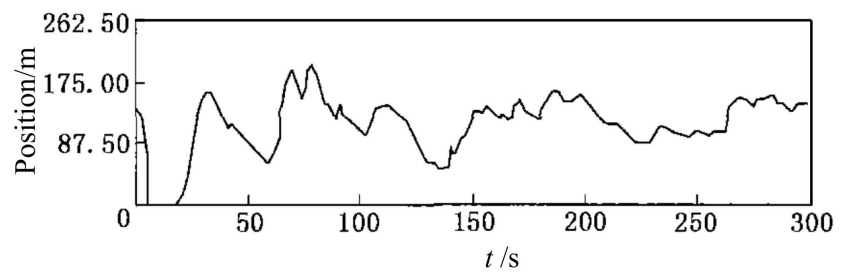

Figure 20. Change process of the interface in the FSPF in the SCTT [38].

In References [35,36], the numerical simulation results were verified by comparing them to the test data based on field measurements. Specifically, in Reference [35], the simulation results for the water hammer pressure under different load rejection conditions were compared to the field measurement results of a real hydropower station. In Reference [36], the simulation results for the water hammer pressure, unit rotation speed, and water level in a tank under load rejection conditions were compared to the results of field measurement.

The numerical simulation methods in References [24,33-38] could realize the calculation of the transient process in HTGSes with SCTTs. The change processes for the important variables, such as water hammer pressure, the interface in the FSPF, working head, rotational speed, and power output, could be obtained. The change rules for those variables were correct. The characteristics of unsteady FSPF in an SCTT could be described reasonably. For numerical simulation methods of the transient process for HTGSes with SCTTs in References [35,36], a comparison with measurements indicated that the error of the simulation results was small. The numerical simulation methods in References $[33,37,38]$ had a fast computation speed, while the numerical simulation methods in References [24,34-36] had good convergence.

\section{Stability of HTGSes with SCTTs}

An HTGS is a core component in regulating the dynamic performance of a hydropower plant [53,54]. The stability of an HTGS directly relates to the stable operation of a hydropower plant $[55,56]$. Because of the effect of an SCTT, the stability of HTGSes with SCTTs is obviously different from that of an HTGS with a pressurized tailrace tunnel. Mathematical modeling, stability analysis methods, and stability performance are key aspects in the study of the stability of HTGSes with SCTTs.

In References [39,40], the stability of HTGSes with SCTTs was studied by using an analytical method. During the transient process, pressurized flow and free surface flow exist simultaneously in an SCTT. The interface in the FSPF moves back and forth. The pressure and discharge spread through the forms of a hammer water wave and a retreated water wave (Figure 21) [39].

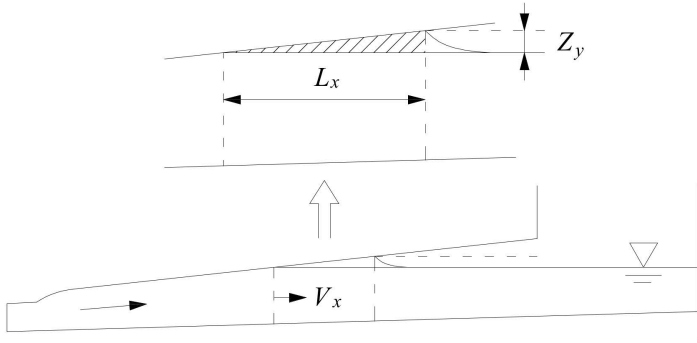

(a)

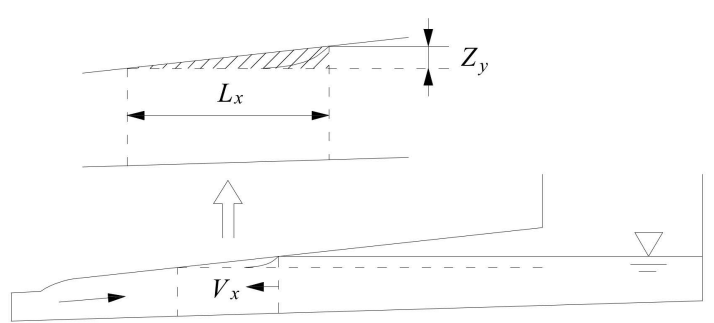

(b)

Figure 21. Interface movement of FSPF in an SCTT. (a) Hammer water wave, (b) retreated water wave. Reproduced with permission from [39], Elsevier, 2015.

Guo et al. [39] proposed a novel dynamic equation of penstock in an SCTT, i.e., Equation (2). Equation (2) can describe the nonlinear characteristics of unsteady FSPF in an SCTT. By combining Equation (2) and the other linear basic equations of a hydropower plant, the nonlinear state equation of HTGSes with SCTTs was established. Then, the stability of HTGSes with SCTTs was analyzed, and the 
effects of factors on stability were revealed. In the stability analysis, the stable domain, bifurcation line (Figure 22), bifurcation diagram, changing tracks of eigenvalues, dynamic response process, and phase space trajectory were given to comprehensively present the dynamic performance of the HTGSes with SCTTs. The section forms of the tailrace tunnel and ceiling slope angle had an obvious effect on the stability of HTGSes with SCTTs. The appropriate section form of the tailrace tunnel and a suitable value for the ceiling slope angle could improve the stability of an HTGS. Equation (2) is

$$
h=-\frac{\lambda Q_{0} V_{x}}{g H_{0} c B \tan \alpha} q \frac{\mathrm{d} q}{\mathrm{~d} t}-T_{w s} \frac{\mathrm{d} q}{\mathrm{~d} t}-\left(\frac{2 h_{f}}{H_{0}}+\frac{\lambda Q_{0}}{H_{0} c B}\right) q .
$$

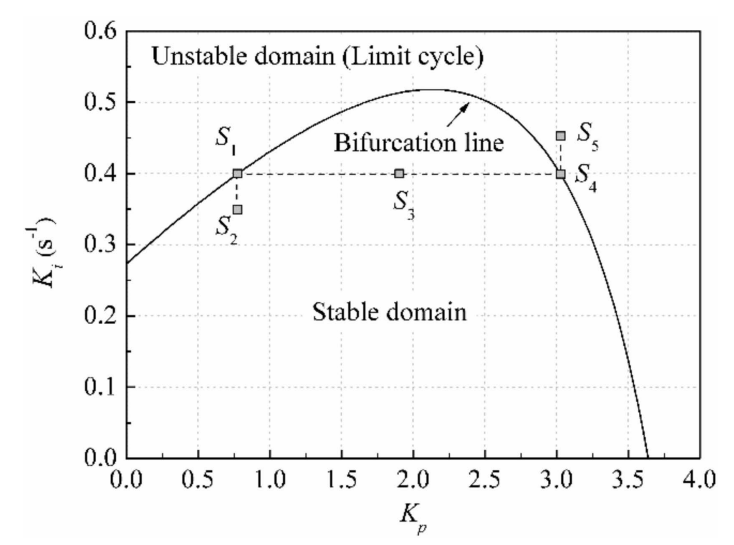

Figure 22. Stable domain and bifurcation line of hydro-turbine governing systems (HTGSes) with SCTTs. Reproduced with permission from [39], Elsevier, 2015.

Based on the nonlinear mathematical model in Reference [39] and Hopf bifurcation theory, Guo et al. [40] investigated the stability working principle of SCTTs under load adjustment. The results indicated that the variation in flow inertia in SCTTs was favorable for stability under load reduction but unfavorable under load increase (Figure 23).

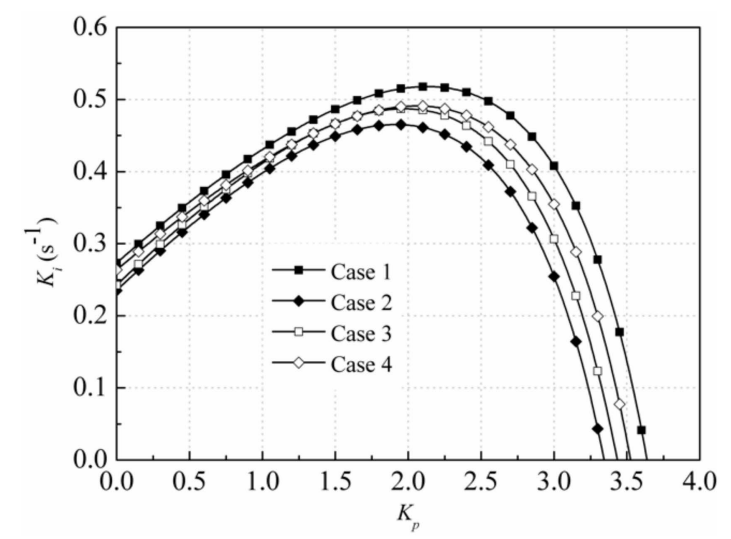

Figure 23. Stable domains of HTGSes with SCTTs under different operating conditions and layouts [40].

The Hopf bifurcation theory was first adopted in a stability analysis of HTGSes with SCTTs $[39,40]$. The effectiveness proved to be excellent. The Hopf bifurcation theory provides a practical method for the analytical analysis of the stability of HTGSes with SCTTs.

In References [41-44], the stability of HTGSes with SCTTs was studied by using the numerical method. Lai et al. [41] investigated the operating stability of a hydro-turbine unit in a hydropower plant with an SCTT by using a numerical simulation based on MATLAB. According to the basic equations of hydropower plants, a block diagram for HTGSes with SCTTs was set up in MATLAB (as shown in 
Figure 24). The stability of HTGSes with SCTTs was analyzed by calculating the dynamic response processes of unit speed under different conditions. The simulation results indicated that the stability of HTGSes with SCTTs could be achieved by selecting the governor parameters reasonably. If the different influence factors, such as the layout of the SCTT and the requirements for regulation quality, are considered comprehensively, the ceiling slope of an SCTT should be valued at 0.04 . The regulation processes of HTGSes with SCTTs are similar to those of HTGSes with surge tanks. There always exists a tail wave in the above two cases. The achievements in Reference [41] provided a basis for the popularization and application of SCTTs.

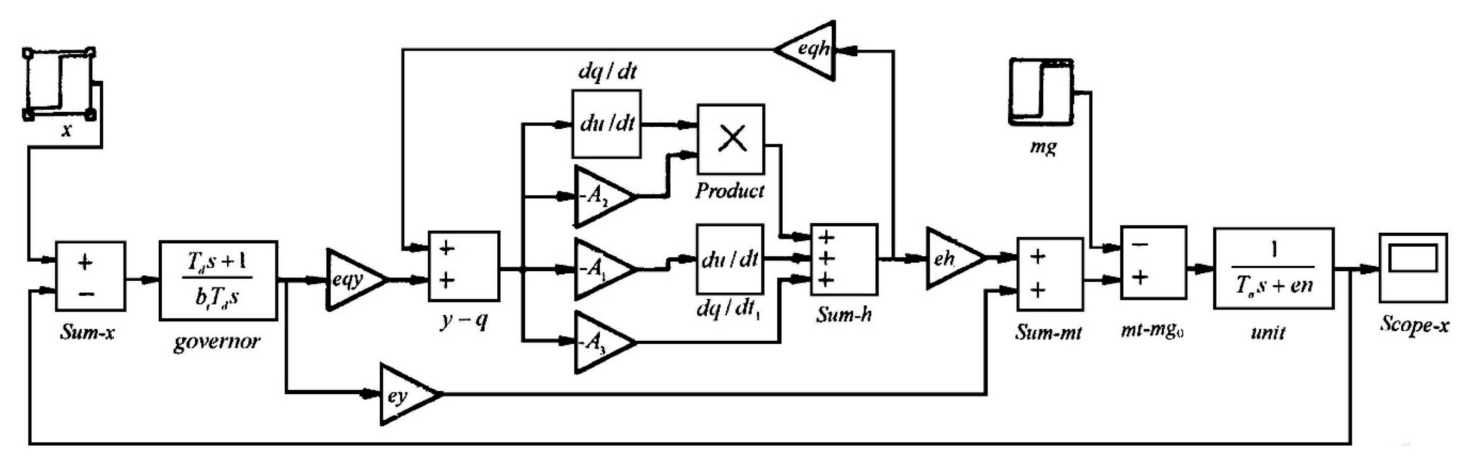

Figure 24. Block diagram of HTGSes with SCTTs [41].

Two hydro-turbine units sharing a tailrace tunnel is a common layout for the pipeline system of a hydropower plant. If the tailrace tunnel is short, an SCTT is a feasible selection scheme to replace a downstream surge tank. For a hydropower plant with two hydro-turbine units sharing an SCTT, Zhou et al. [42] studied the stability of an HTGS under small load disturbance. There are several modules in the numerical simulation model of the stability of an HTGS, including a hydro-turbine unit module, governor module, penstock module, and SCTT module. In view of the above issue, a joint algorithm for the numerical simulation of the stability of an HTGS was proposed [42]. In that joint algorithm, the different modules were solved by using different methods. The method of characteristics for a pressurized pipeline, the improved slot method for open channels, and numerical calculations for state equations were combined. The joint algorithm could reflect the hydraulic characteristics and nonlinear characteristics of different modules and analyze the stability of an HTGS in a time domain. The analysis and comparison results indicated that the stability of the SCTT scheme was obviously better than that of the downstream surge tank scheme.

Li et al. [43] derived a mathematical model for HTGSes with SCTTs from the basic equations for the pipeline, hydro-turbine, and governor. Then, the obtained differential equations were discretized. The iterative method was selected as an improved Euler method to obtain high calculation precision. Based on the mathematical model and numerical simulations, the stability of HTGSes with SCTTs was analyzed. The results indicated that the effect of the ceiling slope of an SCTT on the stability of an HTGS was not obvious when the ceiling slope became greater than a certain value.

In order to study the stability of hydropower plants with complex flow patterns in an SCTT (Figure 25), Zhou et al. [44] introduced a characteristic implicit model to simulate complex flow patterns for further stability analysis. Moreover, a joint method based on both experimental research and numerical simulations was also proposed. In the joint method, the dynamic piezometric head at a given section was obtained by real-time data based on field measurements. Then the stability and regulation performance of the HTGS were analyzed. The time histories of rotational speed were obtained for a detailed regulation performance analysis (as shown in Figure 26). The results indicated that the proposed numerical method could actually reflect the dynamic processes of HTGSes with SCTTs under the effects of complex flow patterns. 

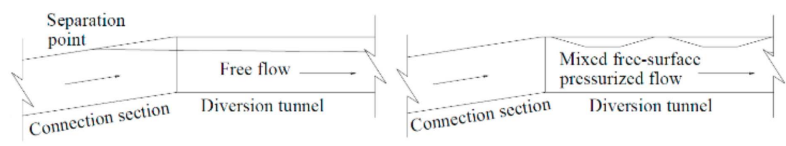

Figure 25. Schematic diagram of the complex flow patterns in an SCTT. Reproduced with permission from [44], ASME, 2013.

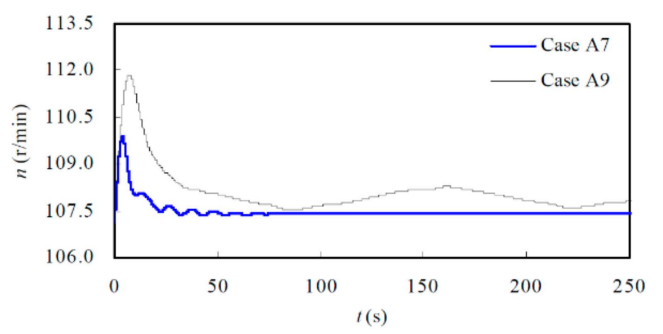

Figure 26. Time histories of rotational speed under load disturbance. Reproduced with permission from [44], ASME, 2013.

In References [39-44], uncertainty and disturbance effects were considered in a stability analysis. During the transient process of a hydropower plant, the water level of free surface flow in an SCTT changes indefinitely. As a result, the working head is an uncertain factor. For uncertainty effects, the uncertainty of a working head was considered during the modeling and analysis process [39-44]. For disturbance effects, different types and values of disturbance were considered and analyzed. In References [39,40], the disturbance was load disturbance. Both positive and negative load disturbances were considered and analyzed. In Reference [41], the disturbance was frequency disturbance. In References [42,44], the disturbance was load disturbance. The regulation performances of hydropower plants with SCTTs under different values of negative load disturbance were analyzed.

\section{Transient Process Control of HTGSes with SCTTs}

Due to the complex flow patterns in an SCTT, the transient process of HTGSes with SCTTs is much more complicated than that of an HTGS with a pressurized tailrace tunnel. The control of transient processes relates to the regulation quality [57-59]. The regulation quality of HTGSes is the basis for the power supply quality of hydropower plants [60-62]. However, the regulation quality of HTGSes with SCTTs under the proportional integral derivative (PID) strategy is poor $[63,64]$. Dynamic performance analysis and control strategies are the focus of attention.

In Reference [45], Guo et al. studied the Hopf bifurcation control of HTGSes with SCTTs using nonlinear state feedback (NSF). Based on NSF with polynomial functions, an NSF control strategy was proposed. The dynamic performance of HTGSes with SCTTs under an NSF control strategy was revealed through an analysis of Hopf bifurcation. The proposed NSF control strategy contains a linear term and a nonlinear term. The linear term can modify the linear stability of the HTGS to eliminate an existing bifurcation. A comparison between the regulation quality of the NSF control strategy and the PID strategy (Figure 27) indicated that the dynamic performance and response speed under the former were obviously better than those under the latter. 


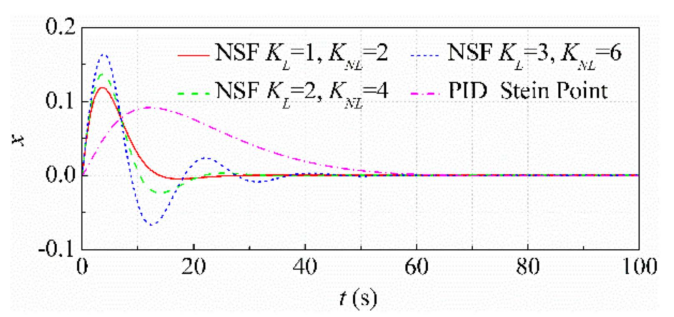

Figure 27. Comparison between the regulation qualities of the nonlinear state feedback (NSF) control strategy and the proportional integral derivative (PID) strategy. Reproduced with permission from [45], Elsevier, 2017.

In Reference [46], Guo studied another nonlinear control strategy, i.e., a nonlinear disturbance decoupling control (NDDC) strategy, for HTGSes with SCTTs. The theoretical basis of the NDDC strategy is differential geometry theory. The NDDC strategy is first adopted into the transient process control of HTGSes with SCTTs. The nominal output function is constructed through a rigorous and complete method. The NDDC strategy for HTGSes with SCTTs is designed by using the nominal output function and then applied to regulate the dynamic process of the system. By using a numerical simulation of the dynamic response process of a hydro-turbine unit frequency, the regulation quality of HTGSes with SCTTs under an NDDC strategy can be evaluated. A comparison between the regulation qualities of the NDDC strategy and the PID strategy showed that the dynamic performance and response speed under the former were obviously better than those under the latter (Figure 28). HTGSes with SCTTs under the NDDC strategy had excellent robustness.

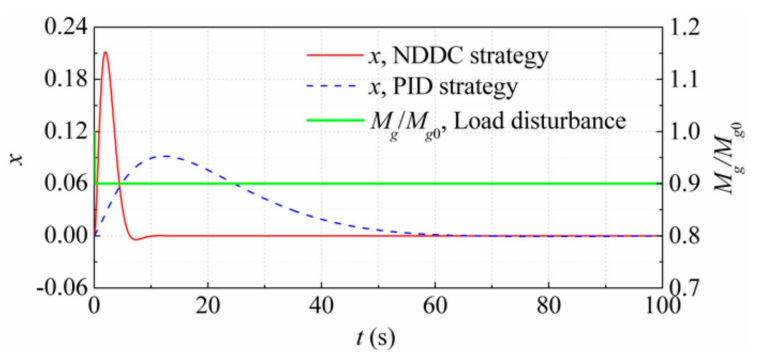

Figure 28. Comparison between the regulation qualities of the nonlinear disturbance decoupling control (NDDC) strategy and the PID strategy [46].

The NSF control strategy and the NDDC strategy are two effective nonlinear control strategies for HTGSes with SCTTs. The advantages of the two strategies are different. A comparison between the regulation qualities of the NSF control strategy and the NDDC strategy indicated that under the NSF control strategy, the response speed was faster, the settling time was shorter, and the attenuation rate of the dynamic response process of the hydro-turbine unit frequency was greater. Under the NDDC strategy, the amplitude of the dynamic response process of the hydro-turbine unit frequency was smaller.

The transient energy variation characteristics of HTGSes are an important tool in revealing system stability. In Reference [47], Zhang et al. established the Hamiltonian function of HTGSes with SCTTs by using generalized Hamiltonian theory. The nonlinear state equation of HTGSes with SCTTs was transformed into the form of a Hamiltonian system. Then the transient energy variation law of the HTGSes with SCTTs was analyzed under three operating conditions, i.e., no load disturbance, step load disturbance, and stochastic load disturbance. The partial results are shown in Figure 29. In Reference [47], HTGSes with SCTTs were brought into the generalized Hamiltonian framework. The internal relevant information of the HTGS can be obtained by analyzing the structure matrix of a generalized Hamiltonian system. The modeling method and numerical simulation in Reference [47] provided a new perspective on the study of the transient energy flow characteristics of HTGSes with SCTTs. 


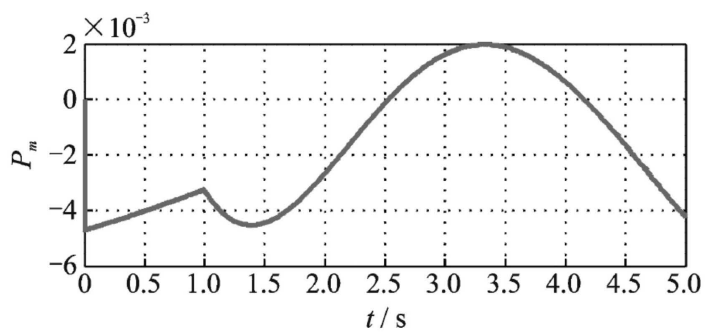

(a)

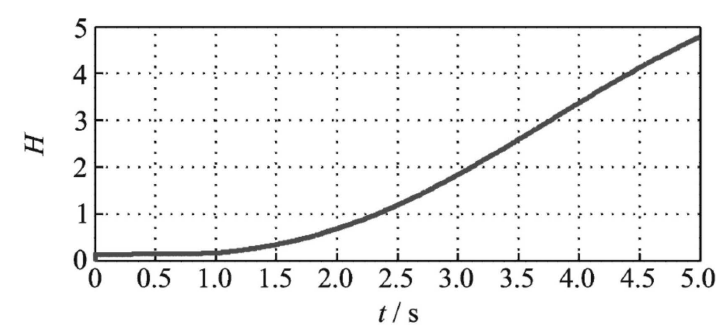

(b)

Figure 29. Variations in unit power output and Hamiltonian functions under the step disturbance of load. (a) Variation in unit power output, (b) variation in Hamiltonian functions [47].

By using the joint methods of field measurement and numerical simulation, Fu et al. [48,49] studies the transient processes of primary frequency regulation for HTGSes with SCTTs in a power regulation mode. The simulation model of HTGSes with SCTTs in a power regulation mode, i.e., Figure 30, contains the state equation of an HTGS and programmable logic controller (PLC) program and measured parameters of governors. The simulation model was verified through a field test. The verified condition was the load increase transient process. The simulation results of guide vane opening, power output, and water hammer pressure were compared to the field experiment results. A three-stage regulation mode, i.e., a slow-fast-slow mode, was proposed to improve the dynamic quality of HTGSes with SCTTs in a power regulation mode. After parameter optimization of the governor, the regulation speed of HTGSes with SCTTs in a power regulation mode increased obviously.

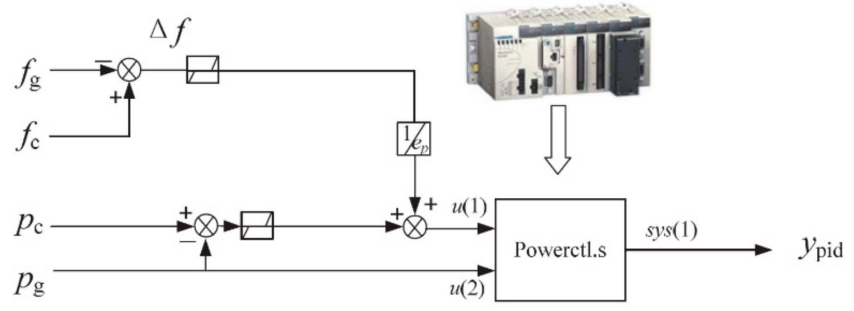

Figure 30. Simulation model of a governor in a power regulation mode in an HTGS [48].

Surge tanks and SCTTs are the two most important pressure reduction facilities in hydropower plants. For a hydropower plant, the surge tank and SCTT can be set synchronously to protect the safe and stable operation of an HTGS. The layout of a hydropower plant with an upstream surge tank and an SCTT is shown in Figure 31, and the layout of a hydropower plant with a downstream surge tank and an SCTT is shown in Figure 32.

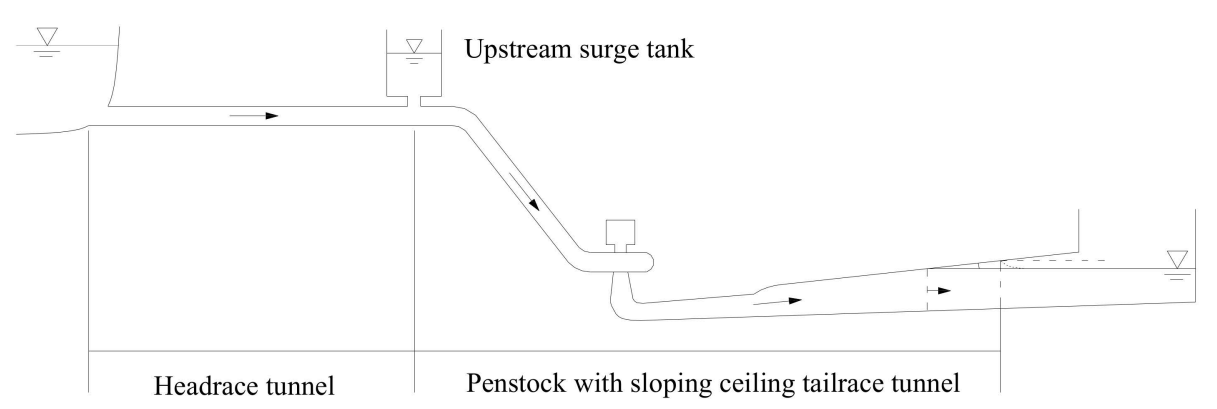

Figure 31. Layout of a hydropower plant with an upstream surge tank and an SCTT. Reproduced with permission from [50], Springer Nature, 2016. 


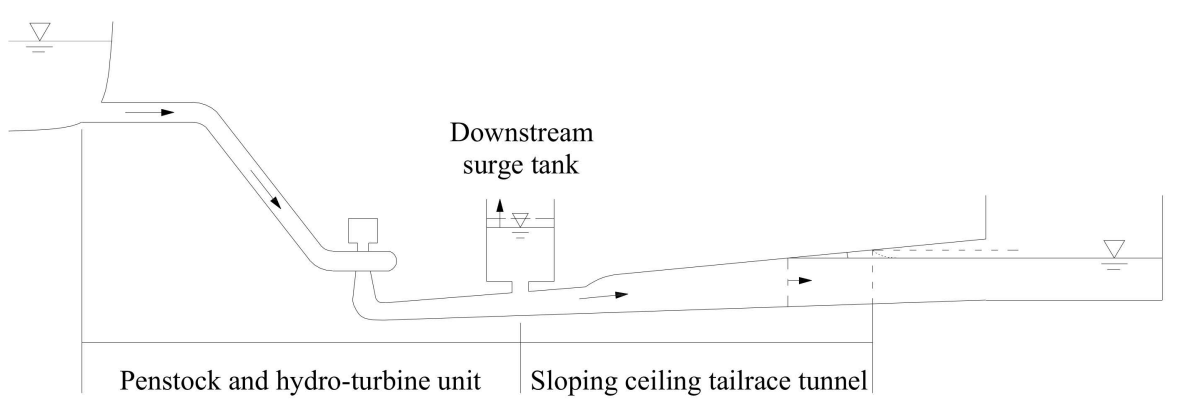

Figure 32. Layout of a hydropower plant with a downstream surge tank and an SCTT. Reproduced with permission from [52], Elsevier, 2018.

Because of the combined effect of a surge tank and an SCTT, the dynamic behavior of an HTGS is extremely complicated. The combined effect mechanism of a surge tank and an SCTT on the dynamic behavior of an HTGS and the transient process control of an HTGS with a surge tank and an SCTT are key issues for the stable operation of a hydropower plant.

In References [50,51], Guo et al. studied the dynamic control of an HTGS with an upstream surge tank and an SCTT and revealed the combined effect of an upstream surge tank and an SCTT on the dynamic performance of an HTGS. Based on the dynamic equation of penstock with an SCTT in Reference [39], a mathematical model of an HTGS with an upstream surge tank and an SCTT was established by combining the basic equations for a headrace tunnel, an upstream surge tank, a hydro-turbine, a governor, and a generator. Then the dynamic performance of an HTGS was analyzed by using the Hopf bifurcation theory. The phase space trajectory of variable responses (Figure 33) could be obtained by solving the state equation of the HTGS, which showed the stability of the system under different state points. The dynamic response processes of the variables in an HTGS showed an obvious feature of wave superposition (Figure 34). There were two bifurcation lines (Figure 35) where the section area of a surge tank was less than the Thoma sectional area.

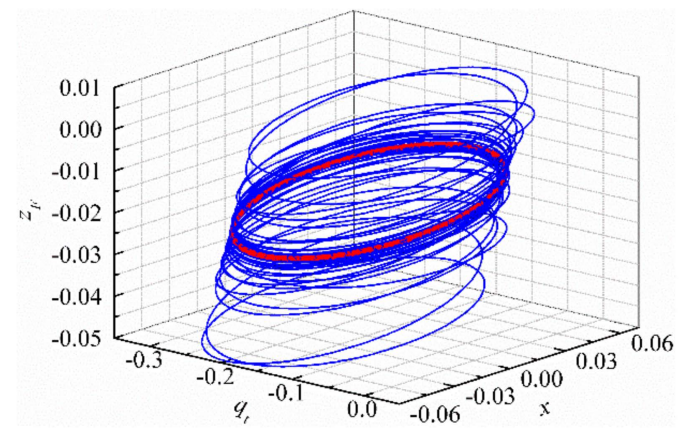

Figure 33. Phase space trajectory of variable responses in an HTGS with an upstream surge tank and an SCTT. Reproduced with permission from [50], Springer Nature, 2016.

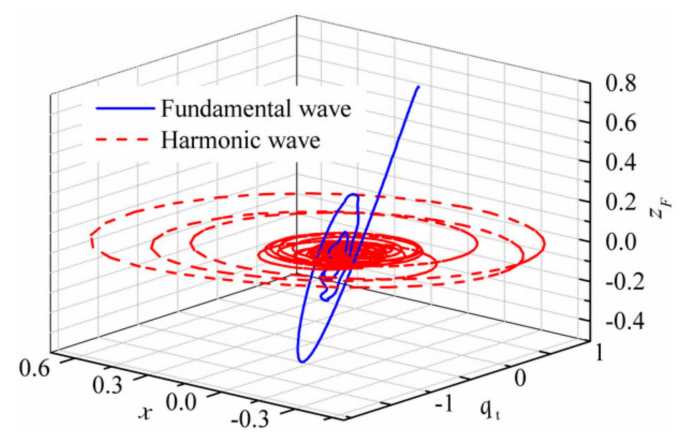

Figure 34. Decomposition of dynamic response processes of variables. Reproduced with permission from [51], Elsevier, 2017. 


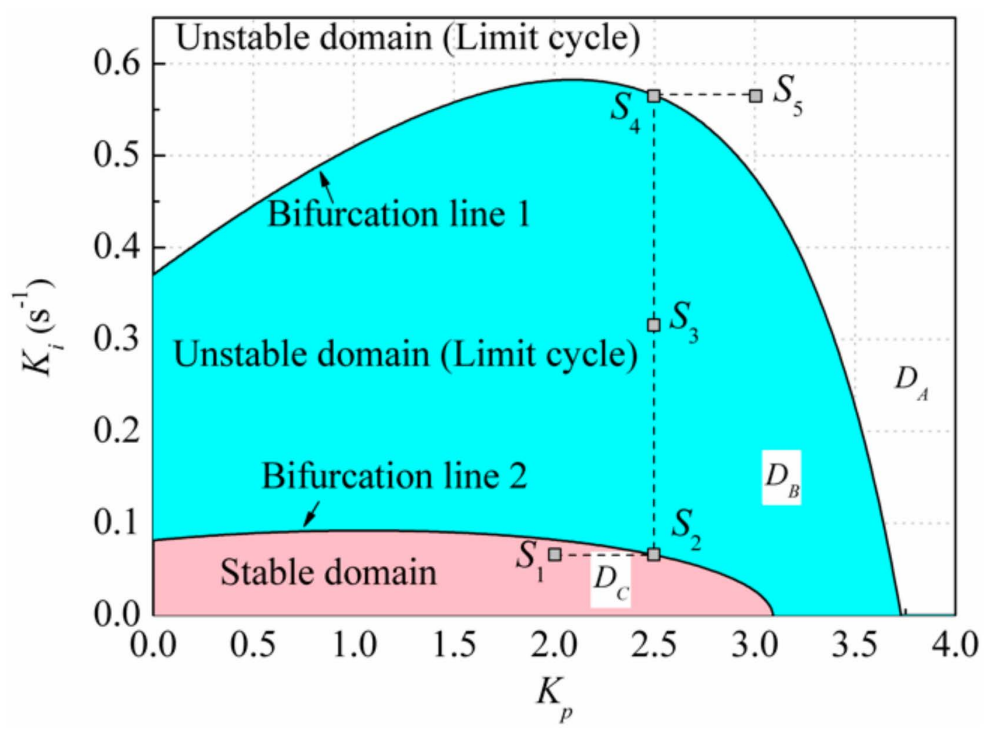

Figure 35. Stable domain and bifurcation lines of an HTGS with an upstream surge tank and an SCTT. Reproduced with permission from [51], Elsevier, 2017.

The dynamic behavior of an HTGS with a downstream surge tank and an SCTT was studied by Guo et al. [52]. Based on the dynamic equation of an SCTT in Reference [39], a mathematical model of an HTGS with a downstream surge tank and an SCTT was established by combining the basic equations of penstock, a downstream surge tank, a hydro-turbine, a governor, and a generator. The adopted analysis theory was also the Hopf bifurcation theory. The effect of the sectional area of the downstream surge tank on the stability of the HTGS was analyzed through the stable domain and phase space trajectory of variable responses (Figure 36). The effect of the aspect ratio of SCTTs on the stability of HTGSes was also analyzed (Figure 37). The results indicated that there was also obvious wave superposition behavior in the dynamic response process of an HTGS with a downstream surge tank and an SCTT. A smaller ceiling slope gradient or a larger aspect ratio could make the downstream surge tank-SCTT subsystem more stable.

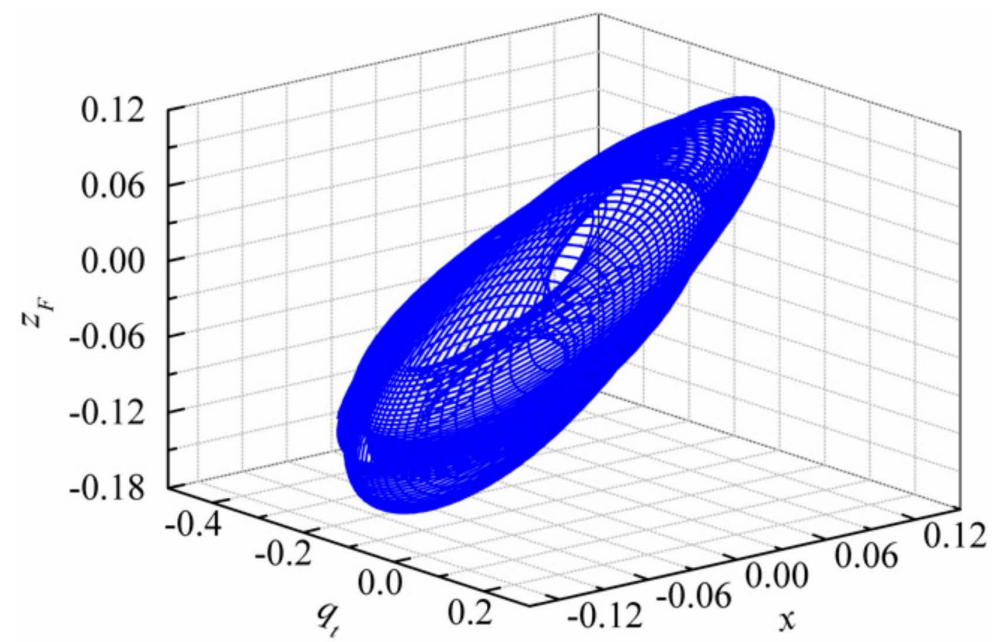

Figure 36. Phase space trajectory of variable responses in an HTGS with a downstream surge tank and an SCTT. Reproduced with permission from [52], Elsevier, 2018. 


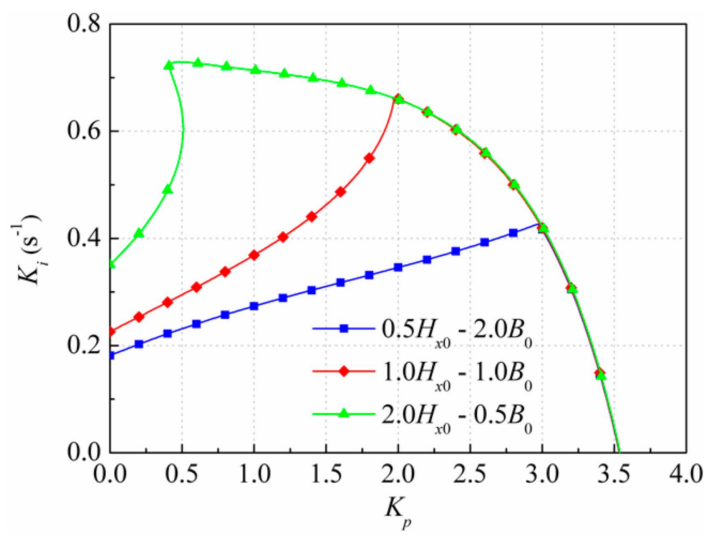

Figure 37. Effect of aspect ratio of an SCTT on the stability of an HTGS. Reproduced with permission from [52], Elsevier, 2018.

In some conditions, a downstream surge tank has to be set, and its sectional area is also extremely large. There are enormous difficulties in excavating, supporting, and stabilizing the surrounding rock of huge underground cavern groups. Compared to the scheme of a hydropower plant with a downstream surge tank, the scheme of a hydropower plant with both a downstream surge tank and an SCTT can reduce the sectional area of a downstream surge tank and improve the stability of a hydropower plant. Then the issue for the layout of a downstream surge tank can be solved. Thus, the primary advantage of a hydropower plant with both a downstream surge tank and an SCTT is the technical aspect, not the economical aspect.

\section{Conclusions}

This review paper gives a systematic literature investigation about the hydraulic transient and dynamic behaviors of hydropower plants with sloping ceiling tailrace tunnels. The conclusions of the review paper are the following:

(1) The working principle of sloping ceiling tailrace tunnel is that a sloping ceiling tailrace tunnel plays the role of a downstream surge tank by using the change in tailwater level. If the variation amplitude of tailwater level is great, it is favorable to adopt a sloping ceiling tailrace tunnel. A sloping ceiling tailrace tunnel can eliminate the problem of minimal pressure at the section of the inlet of draft tube. The typical procedures for the shape design of sloping ceiling tailrace tunnels include five steps to determine the elevation and width of sloping ceiling tailrace tunnels as well as the top elevation of the outlet section and the slopes of the roof and floor;

(2) There is an interface in the free surface pressurized flow in sloping ceiling tailrace tunnels. The length and fluctuation range of the unstable flow section at the interface between free surface flow and pressurized flow are affected by the roof slope and flow velocity of the tailrace tunnel directly. For a numerical simulation of the transient process for hydropower plants with sloping ceiling tailrace tunnels, a joint simulation method that combines the free surface pressurized flow in sloping ceiling tailrace tunnels and conventional hydraulic transient processes is feasible;

(3) The section forms of tailrace tunnels and ceiling slope angles have an obvious effect on the stability of the hydro-turbine governing system in sloping ceiling tailrace tunnels. The regulation process of the hydro-turbine governing system in sloping ceiling tailrace tunnels is similar to that of the hydro-turbine governing system in a surge tank. A nonlinear state feedback control strategy and a nonlinear disturbance decoupling control strategy are two effective nonlinear control strategies for hydro-turbine governing systems in sloping ceiling tailrace tunnels. There is obvious wave superposition behavior in the dynamic response process of hydro-turbine governing systems with upstream/downstream surge tanks and sloping ceiling tailrace tunnels. 
Two future research trends on the hydraulic transient and dynamic behavior of hydropower plant with sloping ceiling tailrace tunnels are pointed out as follows:

(1) The flow in sloping ceiling tailrace tunnels has obvious three-dimensional characteristics. For hydropower plants with sloping ceiling tailrace tunnels, a three-dimensional numerical simulation for the whole flow passage is a future research direction. In a three-dimensional numerical simulation for the whole flow passage, the fluid-solid coupling of the tunnel wall and free surface pressurized flow in sloping ceiling tailrace tunnels are worth studying;

(2) In modern power systems, thermal power, hydropower, and wind power exist simultaneously. For hydropower plants with sloping ceiling tailrace tunnels, a combined operating scheme with thermal power and wind power should be explored.

Funding: This research received no external funding.

Conflicts of Interest: The author declares no conflicts of interest.

\section{Nomenclature}

Hydro-turbine net head, $\mathrm{m}$

Acceleration of gravity, $\mathrm{m} / \mathrm{s}^{2}$

Time, s

Elevation at the inlet of draft tube, $\mathrm{m}$

Pressure at the inlet of draft tube, $m$

Elevation at the interface point of FSPF, $m$

Pressure at the interface point of FSPF, $m$

Initial discharge, $\mathrm{m}^{3} / \mathrm{s}$

Momentum correction coefficient

Vacuum at inlet of draft tube, $m$

Initial elevation of the interface point of FSPF, $m$

Closing time of guide vane, $\mathrm{s}$

Sectional area of tailrace tunnel, $\mathrm{m}^{2}$

Distance, $\mathrm{m}$

Kinetic energy recovery coefficient of draft tube

Movement velocity of the interface point of FSPF, $\mathrm{m} / \mathrm{s}$

Slope of floor

Initial length of the pressurized flow section, $\mathrm{m}$

Unit weight of water

Initial velocity at the inlet of draft tube, $\mathrm{m} / \mathrm{s}$

Relative opening of guide vane

Flow in SCTT

Froude number

Pressure at monitoring point of tailrace tunnel, $\mathrm{m}$

Rotational speed of unit, $\mathrm{r} / \mathrm{min}$

Rated rotational speed of unit, $\mathrm{r} / \mathrm{min}$

Power output of unit, $\mathrm{kW}$

Movement distance of the interface of the FSPF, $\mathrm{m}$

Flow velocity of penstock, the interface of the FSPF, m/s

Change in water level of free surface flow section, $\mathrm{m}$

Wave velocity of free surface flow section, $\mathrm{m} / \mathrm{s}$

Width of SCTT, $\mathrm{m}$

Cross-section coefficient of tailrace tunnel

Steady-state flow inertia time constant, s

Relative hydro-turbine net head

Head loss of penstock, $m$

Relative hydro-turbine discharge 


$\begin{array}{ll}H_{0} & \text { Initial hydro-turbine net head, } \mathrm{m} \\ \alpha & \text { Ceiling slope angle of SCTT } \\ K_{p} & \text { Proportional gain } \\ K_{i} & \text { Integral gain, } \mathrm{s} \\ b_{t} & \text { Temporary droop } \\ T_{d} & \text { Damping device time constant, s } \\ e_{h}, e_{x}, e_{y} & \text { Moment transfer coefficients of hydro-turbine } \\ e_{q h}, e_{q x}, e_{q y} & \text { Discharge transfer coefficients of hydro-turbine } \\ x & \text { Relative hydro-turbine frequency } \\ m_{t} & \text { Relative kinetic moment } \\ m_{g} & \text { Relative resisting moment } \\ M_{g} & \text { Resisting moment, N-m } \\ M_{g 0} & \text { Initial resisting moment, N-m } \\ K_{L} & \text { Coefficient of linear term for NSF control strategy } \\ K_{N L} & \text { Coefficient of nonlinear term for NSF control strategy } \\ f_{c} & \text { Given relative hydro-turbine frequency } \\ f_{g} & \text { Actual relative hydro-turbine frequency } \\ \Delta f & \text { Deviation of relative hydro-turbine frequency } \\ p_{c} & \text { Given relative power output of unit } \\ p_{g} & \text { Actual relative power output of unit } \\ e_{p} & \text { Droop in speed } \\ q_{t} & \text { Relative discharge of penstock } \\ z_{F} & \text { Relative change of water level of upstream surge tank } \\ & \end{array}$

\section{References}

1. Sipahutar, R.; Bernas, S.M.; Imanuddin, M.S. Renewable energy and hydropower utilization tendency worldwide. Renew. Sustain. Energy Rev. 2013, 17, 13-15.

2. Xu, J.P.; Ni, T.; Zheng, B.B. Hydropower development trends from a technological paradigm perspective. Energy Convers. Manag. 2015, 90, 195-206. [CrossRef]

3. Huang, H.L.; Yan, Z. Present situation and future prospect of hydropower in China. Renew. Sustain. Energy Rev. 2009, 13, 1652-1656. [CrossRef]

4. Peng, C.; Qian, G.L. Prospects for the 21st century hydropower development in China. Water Power 2006, 32, 6-10.

5. Chaudhry, M.H. Applied Hydraulic Transients; Springer: New York, NY, USA, 2014.

6. Liu, Q.Z.; Peng, S.Z. Surge Tank of Hydropower Station; China Waterpower Press: Beijing, China, 1995.

7. Peng, Z.Y.; Guo, W.C. Saturation characteristics for stability of hydro-turbine governing system with surge tank. Renew. Energy 2019, 131, 318-332. [CrossRef]

8. Zhu, D.Y.; Guo, W.C. Setting condition of surge tank based on stability of hydro-turbine governing system considering nonlinear penstock head loss. Int. J. Electr. Power 2019, 113, 372-382. [CrossRef]

9. Chanson, H. Hydraulics of Open Channel Flow; Elsevier: Amsterdam, The Netherlands, 2004.

10. Rahman, M.; Chaudhry, M.H. Computation of flow in open-channel transitions. J. Hydraul. Res. 1997, 35, 243-256. [CrossRef]

11. Yang, J.D.; Wang, M.J.; Wang, C.; Guo, W.C. Linear modeling and regulation quality analysis for hydro-turbine governing system with an open tailrace channel. Energies 2015, 8, 11702-11717. [CrossRef]

12. Chaudhry, M.H. Open-Channel Flow; Springer Science \& Business Media: Berlin, Germany, 2007.

13. Krivehenko, G.I.; Kvyatkovskaya, E.V.; Vasilev, A.B.; Vladimirov, V.B. New design of tailrace eonduit of hydropower plant. Hydrotech. Constr. 1985, 19, 352-357. [CrossRef]

14. Kishor, N.; Fraile-Ardanuy, J. Modeling and Dynamic Behaviour of Hydropower Plants; The Institution of Engineering and Technology: Stevenage, UK, 2017.

15. Guo, W.C.; Zhu, D.Y. A review of the transient process and control for a hydropower station with a super long headrace tunnel. Energies 2018, 11, 2994. [CrossRef]

16. Wu, R.Q.; Chen, J.Z. Hydraulic Transients of Hydropower Station; China Water Power Press: Beijing, China, 1997. 
17. Guo, W.C.; Yang, J.D. Modeling and dynamic response control for primary frequency regulation of hydro-turbine governing system with surge tank. Renew. Energy 2018, 121, 173-187. [CrossRef]

18. Yang, J.D.; Chen, J.Z.; Chen, W.B.; Li, S.X. Study on the configuration of hydropower station tailrace tunnel with sloping ceiling. J. Hydr. Eng. 1998, 3, 9-12.

19. Lei, Y.; Yang, J.D.; Lai, X. Experimental study on the hydraulic operating characteristic of hydropower plant tailrace tunnels with sloped top. J. Wuhan Univ. Hydr. Electr. Eng. 1999, 32, 23-27.

20. Lai, X.; Yang, J.D. Study of working characteristics of large hydropower station's tail tunnel with slopping ceiling. Electr. Power 2001, 34, 24-27.

21. Xue, A.Q.; Luo, Y.Q.; Wang, L.; Yan, W. Hydrodynamic characteristics of changing top-altitude tailrace tunnel for Three Gorges Project's underground power plant. J. Yangtze River Scie. Res. Inst. 2001, 18, 9-13.

22. Niu, X.Q.; Yang, J.D.; Xie, H.B.; Wang, H. Technology research and application of inclined roof tailrace tunnel of TGP's underground power station. Yangtze River 2009, 23, 1-4.

23. Miu, M.F.; Zhang, Y.L. Approximate formula for vacuum degree at the inlet of a draft tube in a tailrace with inclined ceiling. J. Hydroelectr. Eng. 2011, 30, 130-135.

24. Deng, M.H.; Liu, D.Y.; Zhou, J.X. Transient flow calculation for sloping ceiling tailwater tunnels and their body-type design for hydropower stations. J. Hohai Univ. (Nat. Sci.) 2003, 31, 436-439.

25. Zhang, Y.L.; Miu, M.F. Method on upper ceiling and configuration design of tailrace tunnel with inclined ceiling. Water Power 2011, 36, 27-29.

26. Zhang, F.; Zhou, S.D.; Li, S.X.; Guo, W. Design of varied roof height tailrace tunnel of Pengshui hydropower station. Yangtze River 2006, 37, 37-38.

27. Gu, X.Y.; Li, F.Y.; Yu, Z.W. Study on the tailrace system with the ceiling height changes of underground powerhouse of Xiangjiaba Hydroelectric Project. Water Power 2004, 30, $23-26$.

28. Li, J.P.; Yang, J.D. Flow regime analysis of free surface-pressurized mixed flow in tailrace tunnel with sloping ceiling. Water Resour. Power 2010, 28, 86-87.

29. An, H.; Yang, J.D. Study on free surface-pressurized flows in tailrace tunnel with sloping ceiling by 1D-3D coupling approach. J. Hydroelectr. Eng. 2015, 34, 108-113.

30. Cheng, Y.G.; Li, J.P.; Yang, J.D. Free surface-pressurized flow in ceiling-sloping tailrace tunnel of hydropower plant: Simulation by VOF model. J. Hydraul. Res. 2007, 45, 88-99. [CrossRef]

31. Zhang, W.; Cai, F.L.; Zhou, J.X.; Hua, Y.L. Experimental investigation on air-water interaction in a hydropower station combining a diversion tunnel with a tailrace tunnel. Water 2017, 9, 274. [CrossRef]

32. Yang, J.D.; Li, L.; Zhou, J.J.; Wang, H. Study on the water flow disruption in the system of tailrace tunnel combined with diversion tunnel. J. Hydrodyn. Ser. A 2012, 27, 394-400.

33. Cheng, Y.G.; Yang, J.D.; Zhang, S.H.; Chen, J.Z. Transient process for free surface-pressurized flow in hydropower plant with ceiling-sloping tailrace tunnel. J. Hydrodyn. Ser. A 1998, 3, 1-6.

34. Zhou, J.X.; Zhang, J.; Liu, D.Y. Hydraulic turbulence calculation for tailwater tunnel system with a sloping ceiling shared by two units. J. Hohai Univ. (Nat. Sci.) 2004, 32, 661-664.

35. Shu, J.; Yuan, J. Transient flow calculation for roof-inclined tailwater tunnel based on L-F slot method. Yangtze River 2014, 45, 73-76.

36. Gui, S.B.; Tian, Z.Q.; Zheng, T.P. Hydraulic transient process numerical prediction and its characteristics study of inclined-roof tailrace tunnel with damping tank. Water Power 2014, 40, 58-61.

37. Wang, J.H.; Li, X.S.; Jiang, H.F. Analysis on tailrace system with varying crown elevation at TGP's right bank underground power station. Yangtze River 2002, 33, 1-3.

38. Zhang, Q.; Liu, B.H. Hydraulic calculation for tailrace tunnel with variable crown heights for underground powerhouse in right abutment at Xiangjiaba Hydropower Station. Water Power 2004, 30, 32-33.

39. Guo, W.C.; Yang, J.D.; Wang, M.J.; Lai, X. Nonlinear modeling and stability analysis of hydro-turbine governing system with sloping ceiling tailrace tunnel under load disturbance. Energy Convers. Manag. 2015, 106, 127-138. [CrossRef]

40. Guo, W.C.; Yang, J.D.; Wang, M.J. Stability analysis of hydro-turbine governing system of hydropower station with inclined ceiling tailrace based on Hopf bifurcation. J. Hydr. Eng. 2016, 47, 189-199.

41. Lai, X.; Chen, J.Z.; Yang, J.D. Stability analysis of hydropower station with inclined ceiling tailrace. J. Hydroelectr. Eng. 2001, 4, 102-107.

42. Zhou, J.X.; Zhang, J.; Liu, D.Y. Study on small fluctuation in system of two units and common tail-tunnel with sloping ceiling. Water Resour. Hydropower Eng. 2004, 35, 64-67. 
43. Li, X.S.; Hu, T.S.; Yu, H.Z.; Dong, X.B. Stability analysis and research of transient process caused by small fluctuation in inclined ceiling tailrace structure. Water Resour. Power 2005, 23, 28-30.

44. Zhou, J.X.; Cai, F.L.; Hu, M. Stability analysis of hydropower stations with complex flow patterns in the tailrace tunnel. In Proceedings of the ASME 2013 Fluids Engineering Division Summer Meeting, Incline Village, NV, USA, 7-11 July 2013.

45. Guo, W.C.; Yang, J.D. Hopf bifurcation control of hydro-turbine governing system with sloping ceiling tailrace tunnel using nonlinear state feedback. Chaos Soliton Fract. 2017, 104, 426-434. [CrossRef]

46. Guo, W.C. Nonlinear disturbance decoupling control for hydro-turbine governing system with sloping ceiling tailrace tunnel based on differential geometry theory. Energies 2018, 11, 3340. [CrossRef]

47. Zhang, H.; Xu, B.B.; Chen, D.Y. Hamiltonian model of a hydro-turbine governing system with inclined ceiling tailrace. J. Vib. Eng. 2018, 31, 323-328.

48. Fu, L. Optimization of governor power mode for hydro-turbine units with slope ceiling tail tunnels. J. Hydroelectr. Eng. 2018, 37, 88-95.

49. Fu, L.; Wu, C.L.; Tang, W.P. Hydro turbine governor's power control of hydroelectric unit with sloping ceiling tailrace tunnel. IOP Conf. Ser. Earth Environ. Sci. 2018, 121, 042009. [CrossRef]

50. Guo, W.C.; Yang, J.D.; Chen, J.P.; Wang, M.J. Nonlinear modeling and dynamic control of hydro-turbine governing system with upstream surge tank and sloping ceiling tailrace tunnel. Nonlinear Dynam. 2016, 84, 1383-1397. [CrossRef]

51. Guo, W.C.; Yang, J.D. Combined effect of upstream surge chamber and sloping ceiling tailrace tunnel on dynamic performance of turbine regulating system of hydroelectric power plant. Chaos Soliton Fract. 2017, 99, 243-255. [CrossRef]

52. Guo, W.C.; Yang, J.D. Dynamic performance analysis of hydro-turbine governing system considering combined effect of downstream surge tank and sloping ceiling tailrace tunnel. Renew. Energy 2018, 129, 638-651. [CrossRef]

53. Guo, W.C.; Yang, J.D.; Yang, W.J.; Chen, J.P.; Teng, Y. Regulation quality for frequency response of turbine regulating system of isolated hydroelectric power plant with surge tank. Int. J. Electr. Power 2015, 73, 528-538. [CrossRef]

54. Guo, W.C.; Yang, J.D.; Chen, J.P.; Yang, W.J.; Teng, Y.; Zeng, W. Time response of the frequency of hydroelectric generator unit with surge tank under isolated operation based on turbine regulating modes. Electr. Power Compon. Syst. 2015, 43, 2341-2355. [CrossRef]

55. Guo, W.C.; Yang, J.D. Stability performance for primary frequency regulation of hydro-turbine governing system with surge tank. Appl. Math. Modell. 2018, 54, 446-466. [CrossRef]

56. Guo, W.C.; Peng, Z.Y. Hydropower system operation stability considering the coupling effect of water potential energy in surge tank and power grid. Renew. Energy 2019, 134, 846-861. [CrossRef]

57. Wei, S.P. Hydraulic Turbine Regulation; Huazhong University of Science and Technology Press: Wuhan, China, 2009.

58. Lai, X.J.; Li, C.S.; Guo, W.C.; Xu, Y.H.; Li, Y.G. Stability and dynamic characteristics of the nonlinear coupling system of hydropower station and power grid. Commun. Nonlinear Sci. 2019, 79, 104919. [CrossRef]

59. Zhu, D.Y.; Guo, W.C. Critical sectional area of surge chamber considering nonlinearity of head loss of diversion tunnel and steady output of turbine. Chaos Soliton Fract. 2019, 127, 165-172. [CrossRef]

60. Xu, B.B.; Chen, D.Y.; Behrens, P.; Ye, W.; Guo, P.C.; Luo, X.Q. Modeling oscillation modal interaction in a hydroelectric generating system. Energy Convers. Manag. 2018, 174, 208-217. [CrossRef]

61. IEEE Working Group. Hydraulic turbine and turbine control model for system dynamic studies. IEEE Trans. Power Syst. 1992, 7, 167-179. [CrossRef]

62. Xu, B.B.; Chen, D.Y.; Zhang, H.; Zhou, R. Dynamic analysis and modeling of a novel fractional-order hydro-turbine-generator unit. Nonlinear Dynam. 2015, 81, 1263-1274. [CrossRef]

63. Chen, Z.H.; Yuan, X.H.; Ji, B. Design of a fractional order PID controller for hydraulic turbine regulating system using chaotic non-dominated sorting genetic algorithm II. Energy Convers. Manag. 2014, 84, 390-404. [CrossRef]

64. Chen, Z.H.; Yuan, Y.B.; Yuan, X.H.; Huang, Y.H.; Li, X.S.; Li, W.W. Application of multi-objective controller to optimal tuning of PID gains for a hydraulic turbine regulating system using adaptive grid particle swam optimization. ISA Trans. 2015, 56, 173-187. [CrossRef]

(C) 2019 by the author. Licensee MDPI, Basel, Switzerland. This article is an open access article distributed under the terms and conditions of the Creative Commons Attribution (CC BY) license (http://creativecommons.org/licenses/by/4.0/). 